US Army Corps

of Engineers

Waterways Experiment

Station

Natural Resources Research Program

\title{
Ethnicity, Race, and Outdoor Recreation: A Review of Trends, Policy, and Research
}

by James H. Gramann

Texas A\&M University

Approved For Public Release; Distribution Is Unlimited

Prepared for Headquarters, U.S. Army Corps of Engineers 
The contents of this report are not to be used for advertising, publication, or promotional purposes. Citation of trade names does not constitute an official endorsement or approval of the use of such commercial products.

The findings of this report are not to be construed as an official Department of the Army position, unless so designated by other authorized documents. 


\section{Ethnicity, Race, and Outdoor Recreation:}

A Review of Trends, Policy, and Research

by James H. Gramann

Department of Recreation, Park, and Tourism Sciences

Department of Rural Sociology

Texas A\&M University

College Station, TX $77843-2261$

Final report

Approved for public release; distribution is unlimited

Prepared for U.S. Army Corps of Engineers

Washington, DC 20314-1000

Under $\quad$ Work Unit 32992

Monitored by U.S. Army Engineer Waterways Experiment Station 3909 Halls Ferry Road

Vicksburg, MS 39180-6199 


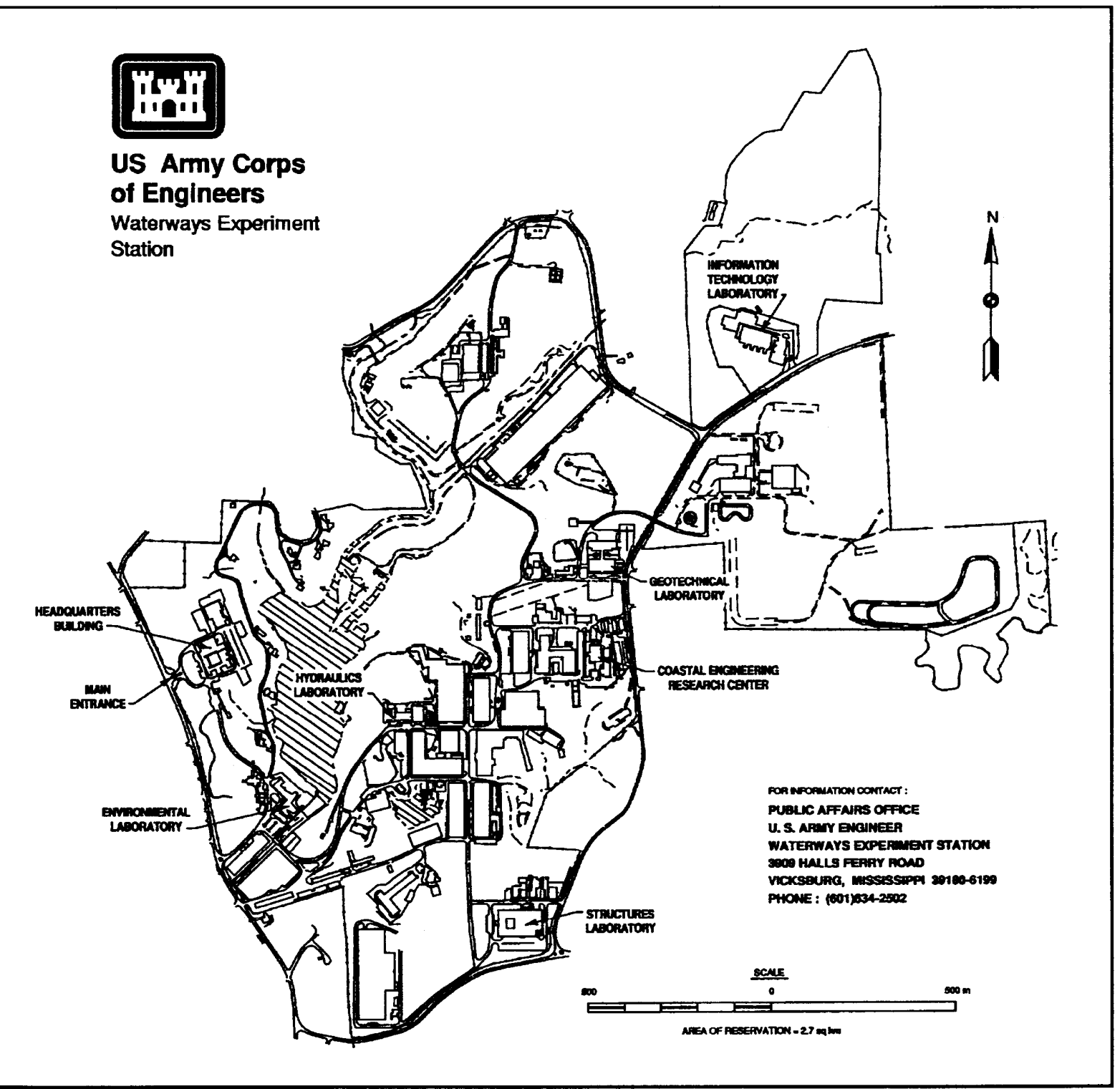

\section{Waterways Experiment Station Cataloging-in-P ublication Data}

Gramann, James $\mathrm{H}$.

Ethnicity, race, and outdoor recreation : a review of trends, policy, and research / by James H. Gramann ; prepared for U.S. Army Corps of Engineers ; monitored by U.S. Army Engineer Waterways Experiment Station.

88 p. : ill. ; $28 \mathrm{~cm}$. - (Miscellaneous paper ; R-96-1)

Includes bibliographic references.

1. Outdoor recreation - Public use. 2. Recreation - United States - Public use. 3. Ethnicity. 4. Minorities - Study and training. I. United States. Army. Corps of Engineers. II. U.S. Amy Engineer Waterways Experiment Station. III. Natural Resources Research Program (US Army Corps of Engineers) IV. Miscellaneous paper (U.S. Army Engineer Waterways Experiment Station) ; R-96-1.

TA7 W34m no.R-96-1 


\section{Contents}

Preface $\ldots \ldots \ldots \ldots \ldots \ldots \ldots \ldots \ldots \ldots \ldots \ldots$ vi

Summary $\ldots \ldots \ldots \ldots \ldots \ldots \ldots \ldots \ldots \ldots \ldots \ldots$ viii

1-Introduction $\ldots \ldots \ldots \ldots \ldots \ldots \ldots \ldots \ldots \ldots \ldots$

2-Demographic Trends . . . . . . . . . . . . . . . 3

Defining Race and Ethnicity ................. 3

Current Ethnic Composition of the United States . . . . . . . . 4

Projected Ethnic Composition of the United States . . . . . . . . 5

Population Growth in Nonmetropolitan Areas $\ldots \ldots \ldots \ldots \ldots$

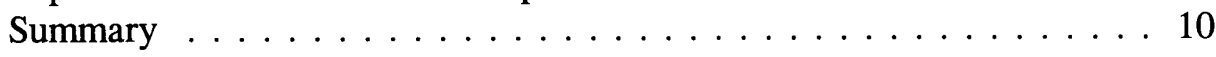

3-Ethnic Diversity and Public Policy $\ldots \ldots \ldots \ldots \ldots \ldots \ldots 12$

Executive Order 12862: Setting Customer Service Standards . . . . . 13

Executive Order 12898: Federal Actions to Address Environmental

Justice in Minority Populations and Low-Income Populations . . . . 14

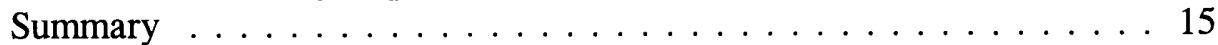

4-Ethnicity Research by Federal Recreation Resource Management

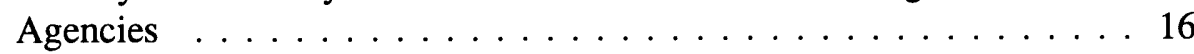

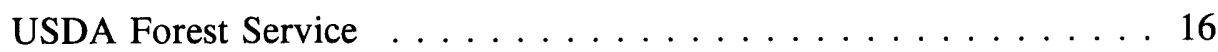

USDI National Park Service $\ldots \ldots \ldots \ldots$. . . . . . . . . . . . 17

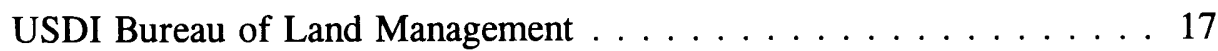

U.S. Fish and Wildlife Service $\ldots \ldots \ldots \ldots \ldots \ldots \ldots \ldots \ldots$

U.S. Army Corps of Engineers $\ldots \ldots \ldots \ldots \ldots \ldots \ldots \ldots$

Summary . . . . . . . . . . . . . . . . . . . . 19

5-Overview of Major Research Themes in Ethnicity, Race, and

Outdoor Recreation . . . . . . . . . . . . . . . . . . . 20

Underparticipation and Underutilization $\ldots \ldots \ldots \ldots \ldots \ldots$

Outdoor Recreation Style . . . . . . . . . . . . . . . . 21

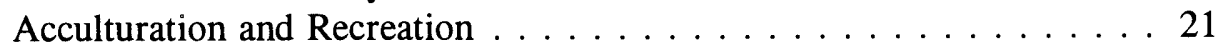

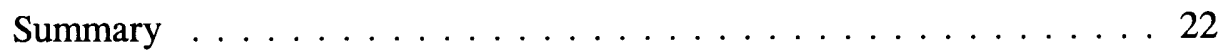

$6-$ Research on Underparticipation and Underutilization . . . . . . 23

Marginality and Ethnicity Hypotheses . . . . . . . . . . . . 23

Ethnic Differences in Activity Participation . . . . . . . . . . . . 27 
Ethnic Differences in Travel to and Use of Outdoor

Recreation Areas . . . . . . . . . . . . . . . . 31

Perceived Discrimination and Underutilization . . . . . . . . . 32

Projections of Future Activity Participation . . . . . . . . . . . 35

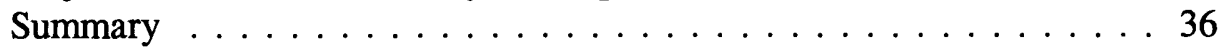

7-Research on Ethnic Differences in Recreation Style . . . . . . . . . . 38

Size and Composition of Social Groups . . . . . . . . . . . 38

Participation Motives . . . . . . . . . . . . . . . . 39

Language . . . . . . . . . . . . . . . . . . . . . . 40

Attitudes Toward Natural Resources and Facility Development . . . . 41

Summary . . . . . . . . . . . . . . . . 47

8 -Research on Acculturation and Recreation $\ldots \ldots \ldots 48$

Selective Acculturation . . . . . . . . . . . . . . 49

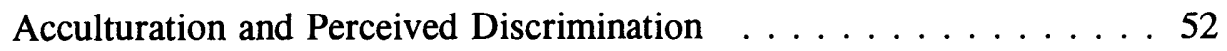

Summary . . . . . . . . . . . . . . . 53

9-Applications of Recreation Ethnicity Research . . . . . . . . . . . 55

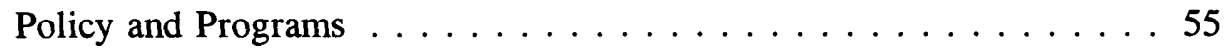

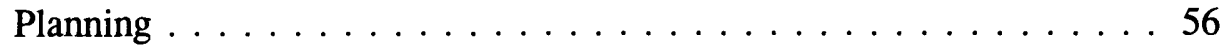

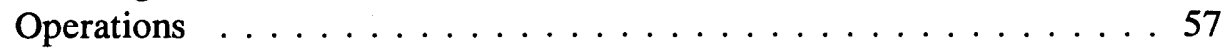

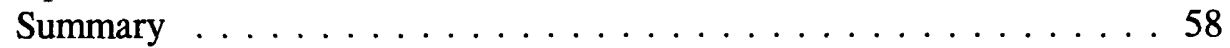

10-Research Needs . . . . . . . . . . . . . . . . . . 59

References ..........................661

SF 298

\section{List of Tables}

Table 1. Percent Race/Ethnic Group in Southwestern and Pacific States-1993 Estimates . . . . . . . . . . . . . . 5

Table 2. Percent Race/Ethnic Group in Southeastern States-1993

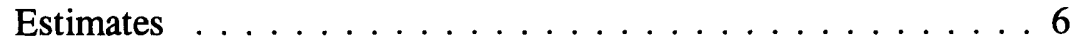

Table 3. Percent Race/Ethnic Group in Great Lakes and Mid-Atlantic

States-1993 Estimates . . . . . . . . . . . . . . 7

Table 4. Percent Race/Ethnic Group in Southwestern and Pacific States-2020 Projections . . . . . . . . . . . . . . . . 8

Table 5. Percent Race/Ethnic Group in Southeastern States-2020

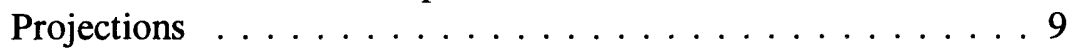

Table 6. Percent Race/Ethnic Group in Great Lakes and Mid-Atlantic States-2020 Projections . . . . . . . . . . . . . . . . 10 
Table 7. Population Change, Net Migration, and Natural Increase in Nonmetropolitan Counties by Selected

Variables-1990 to $1992 \ldots \ldots \ldots \ldots \ldots 11$ 


\section{Preface}

The work reported herein was conducted as part of the Natural Resources Research Program (NRRP), Work Unit 32992. The NRRP is sponsored by the Headquarters, U.S. Army Corps of Engineers (HQUSACE), and is assigned to the U.S. Army Engineer Waterways Experiment Station (WES) under the purview of the Environmental Laboratory (EL). Funding was provided under Department of the Army Appropriation No. 36X3121, General Investigation. The NRRP is managed under the Environmental Resources Research and Assistance Programs (ERRAP), Mr. J. L. Decell, Manager. Mr. Russell K. Tillman was Assistant Manager, ERRAP, for the NRRP. Program monitors during this study were Messrs. Robert Daniel and David J. Wahus, HQUSACE. Mr. Phil Turner, South Pacific Division, is the NRRP Field Review Group Proponent for the work unit.

The report documents a review of literature covering participation in outdoor recreation by ethnic minorities. This literature review is the initial work in the Ethnic Culture and Recreation Use Work Unit. The review was prepared under purchase order by Dr. James H. Gramann, Department of Recreation, Park, and Tourism Sciences, Texas A\&M University, College Station, TX. This work was initiated and monitored by Mr. Jim E. Henderson, Resource Analysis Branch (RAB), EL, the Principal Investigator for the Ethnic Culture and Recreation Use Work Unit.

This report was prepared under the general supervision of Mr. H. Roger Hamilton, Chief, RAB; Dr. Robert M. Engler, Chief, Natural Resources Division, EL; and Dr. John W. Keeley, Director, EL.

At the time of publication of this report, Director of WES was Dr. Robert W. Whalin. Commander was COL Bruce K. Howard, EN. 
This report should be cited as follows:

Gramann, J. H. (1996). "Ethnicity, race, and outdoor recreation: A review of trends, policy, and research," Miscellaneous Paper R-96-1, U.S. Army

Engineer Waterways Experiment Station, Vicksburg, MS.

The contents of this report are not to be used for advertising, publication, or promotional purposes. Citation of trade names does not constitute an official endorsement or approval of the use of such commercial products. 


\section{Summary}

Differences in outdoor recreation behavior of ethnic groups has been the subject of research in the United States for more than 30 years. This report reviews the social science literature describing ethnic and racial differences in recreation and leisure behavior and summarizes the national policy context for that research. Major sections of the review included demographic trends in the ethnic and racial composition of the United States; national ethnic policy as reflected in the statutes and regulations of the United States, including two recent executive orders that are especially relevant to ethnicity, race, and outdoor recreation; a review of current research programs on ethnicity and recreation in the major Federal recreation resource management agencies; overview of major research issues in studies of ethnicity and recreation and recent applications of recreation ethnicity research to policy and program development, planning, and operations in Federal and State resource management agencies.

A major criticism of much research comparing the recreation patterns of different cultural groups is that researchers have interpreted racial differences as ethnic differences, thus confounding these two distinct concepts. Ethnicity is usually defined as membership in a subcultural group on the basis of country of origin, language, religion, or cultural traditions. Race on the other hand is based on socially constructed definitions of physical appearance. Members of an ethnic group share a common cultural tradition (as opposed to racial characteristics) and also have some degree of consciousness of being different from other such groups. The U.S. Census Bureau employs five racial/ethnic groupings in its population estimates and projections. These are "white," "black," "Asian and Pacific Islander," "American Indian, Eskimo, and Aleut," and "Hispanic origin." The first four of these are racial categories, while the last is an ethnic category that includes Hispanics of all racial groups.

Because the probability of participating in certain types of outdoor recreation activities is affected by a person's race and ethnicity, it is important to be aware of geographic patterns in the nation's ethnic composition, as well as major trends in the growth of different ethnic groups. The demographic profile of the United States is changing toward a more ethnically and geographically diverse population. Although Asian-origin and African-American groups should increase significantly in numbers over the next 25 years, the 
ethnic transformation of the United States is being driven primarily by the rapid growth of its Hispanic population. This growth is being experienced in a relatively restricted geographic region, composed of the States adjacent to or near the U.S.-Mexico border. However, other pockets of strong Hispanic growth are occurring in south Florida, the industrial States of the Northeast, and in Illinois.

Growth in population of nonmetropolitan counties is also occurring, reversing a decade of decline during the 1980s. An increase in net in-migration to counties with recreation-dominated economies and to rural retirement destinations is one factor underlying nonmetropolitan growth in the U.S. Even so, the greatest population increases continue to be in metropolitan counties.

National policies concerning ethnic diversity fall into two broad categories. "Pluralism" describes a continuum of polecats that, to varying degrees, encourage retention of ethnic differences within a single political system. In contrast, "assimilation" is a policy that seeks to reduce or eliminate cultural distinctions within society.

Assimilation is generally characterized as cultural assimilation and structural assimilation. Cultural assimilation refers to an ethnic minority's acceptance of the dominant cultural pattern of the host society (e.g., language, religion, diet, dress, and child-rearing practices). In contrast, structural assimilation refers to the social, economic, and political integration of ethnic minorities into mainstream society. The aim of the latter policy is to guarantee equal access of all groups to society's major institutions, such as education, the economy, and government, including public recreation areas. The U.S. clearly has a policy of structural assimilation with respect to its ethnic minorities.

Of the major Federal recreation resource management agencies, only the U.S. Department of Agriculture Forest Service has an institutionalized research focus that explicitly addresses management and social science issues pertaining to ethnicity, race, and outdoor recreation. The National Park Service and U.S. Fish and Wildlife Service often collect data on the ethnicity or race of visitors, but this is rarely the primary purpose of their research. Consequently, analyses of these data have been limited.

Early research in ethnicity and outdoor recreation focused on underparticipation and underutilization of recreation areas by members of ethnic minorities. Although underparticipation certainly has not disappeared as a policy issue, research indicates that it may be less relevant in the case of some ethnic groups, and that the focus and concern is on problems arising from differences in styles of recreational use between ethnic groups, rather than on underutilization.

Recreation style is the unique quality of recreation behavior that arises from variations between ethnic groups in group size, participation motives, spoken language, and attitudes toward natural resources, including 
facility-development preferences. The concern with ethnic variation in recreation style frequently reflects fears on the part of resource managers that the behaviors of some groups may result in inferior recreation experiences, facility damage, and resource degradation.

A major criticism of many recreation studies is that they have treated ethnic and racial groups as a culturally homogeneous block. This is especially problematic in the case of Hispanic Americans and Asian Americans, who represent more than a score of different national-origin groups. Research has shown that the more generations Mexican Americans can trace back their U.S. ancestry, the greater their degree of assimilation into Anglo culture. Because Mexican immigration to the U.S. is an ongoing phenomenon, the dynamics of acculturation, together with cultural heterogeneity it produces, will continue to result in an ethnically diverse Mexican-American population. Less prominent in research on ethnicity and leisure to date have been studies of the recreation behavior and styles of Asian Americans and native Americans.

Early research into underparticipation and underutilization focused on differences between African Americans and whites in both rural and urban recreation participation. In general, black minorities were found to have lower participation rates than whites. This was attributed to the lower socioeconomic position of African Americans in a white-dominated society. However, it was also found that when socioeconomic variables were controlled, participation differences between the two racial groups persisted, suggesting that subcultural preferences also were important in explaining variation in recreation behavior.

The above findings about differences in participation by racial groups led to the development of two contrasting explanations. The first explanation has come to be known as the marginality hypothesis. This hypothesis states that the "underparticipation" of blacks in outdoor recreation results primarily from limited economic resources, which in turn are a function of historical patterns of discrimination. The second explanation is known as the ethnicity hypothesis. This hypothesis states that minority underparticipation results from culturally based differences between ethnic groups in values, system norms, and leisure socialization patterns. According to this view, these cultural forces, rather than socioeconomic factors, are more significant in explaining differences between blacks and whites in recreation behavior.

Studies are summarized that have examined various aspects of the marginality-ethnicity framework. The studies suggest that cultural preferences may sometimes interact with socioeconomic status to affect recreation behavior. When people have very limited access, resources, and opportunity, their participation rates in inaccessible and relatively expensive outdoor recreation activities tend to be low, regardless of their racial or ethnic background. Similarly, when there are few constraints on access, participation rates may be high, irrespective of race or ethnicity. However, between these two extremes, participation differences between blacks and whites often exist, even when 
socioeconomic factors are controlled. This implies that subcultural preferences play a significant role in determining many, although by no means all, forms of outdoor recreation behavior.

Studies that have not adopted the marginality-ethnicity approach and do not control for socioeconomic differences have found many similarities, as well as differences, in leisure behavior. In general, fewer differences in outdoor recreation behavior have been reported between whites and Hispanics than between whites and African Americans. Asian Americans also tend to be more like whites than blacks in their recreation behavior. In the case of consumptive wildlife activities, such as hunting and fishing, similarities in participation rates may mask ethnically based differences in the meanings of these activities. Specifically, members of some groups, including ethnic minorities and still occasionally Anglo, use hunting and fishing as a form of subsistence, rather than as a form of recreation.

Studies of ethnic differences in the utilization of different types of outdoor recreation areas (as contrasted with participation in recreation activities) tend to mirror the results of research on participation rates. In general, black Americans are less likely than whites to visit areas such as national parks. In the U.S., adult blacks are significantly less likely than whites, Hispanics, or members of other ethnic groups to visit national or state parks, historic sites, or museums. In general, African Americans tend to stay closer to home than whites when engaging in outdoor recreation. Whites are more likely to travel for recreation, while African Americans are least likely, with other racial and ethnic groups falling in between. The tendency for minority-group members to travel shorter distances for recreation is also seen in comparisons between Anglo Americans and Hispanic Americans. The trend is not as clear-cut as it is in black-white comparisons.

Generally speaking, a higher percentage of white Americans tend to participate in recreation activities than do African Americans. One frequent exception to this pattern is fishing and hunting. In some studies, blacks and whites have been found to participate at equal rates in both of these activities, while in other research, minority groups have participated at higher rates. One explanation for this pattern is that fishing is an outdoor activity that may be done for sustenance by some low-income minority groups. Another explanation for the popularity of fishing and hunting to blacks is that African Americans have a long tradition of participating in these activities that dates back to the slavery period. A similar tradition of participation does not exist for may other contemporary outdoor recreation activities.

In terms of both recreation participation and recreational travel, Hispanic Americans and Asian Americans tend to be more similar to Anglos than they are to blacks. However, very little data are available on the recreation participation and utilization patterns of Asian Americans. Some differences that exist between Hispanics and Anglos appear to be due to the younger age of the Hispanic population. When age is controlled in participation-rate 
comparisons, many of the differences between Anglos and Hispanics become insignificant.

Research on the causes of participation-rate differences between whites and members of other ethnic groups provides mixed support of the ethnicity and marginality explanations. Various ethnic and racial minorities in the U.S. appear to have evolved different culturally based preferences for at least some types of outdoor recreation activities. However, there also exists a set of highly accessible leisure pursuits that are popular among all segments of the U.S. population, regardless of ethnic or racial background.

One recently investigated explanation for ethnic differences in the utilization of parks and other recreation areas is perceived discrimination, either from staff, other users, or law informant officers. The few studies that exist suggest that perceptions by blacks and other minority groups that they are "unwelcome" by whites may reduce their travel to some areas. However, much of the evidence for a discrimination effect is anecdotal.

The effect of ethnicity on recreation participation has been examined in projections of future demand for outdoor activities. These studies indicate that, taken together, ethnicity and age play an important role in shaping future demand and that caution is needed in assuming that participation rates characteristic of a specific age or ethnic cohort at one point in time will not change.

Research on ethnic differences in recreation style has emphasized distinctions between Anglos and Hispanics. In general, Hispanic Americans are more likely than Anglos to participate in outdoor recreation activities as members of large social groups, including extended families.

Many Hispanic Americans are bilingual, while others speak primarily Spanish. However, for most Hispanics, the ability to read and write in Spanish is not as well developed as their skills in speaking Spanish. This indicates that Spanish-language communication with Hispanic visitors will be more effective if it is in the form of oral communications rather than written communication.

The Hispanic relationship to the natural work seems to be one that incorporates human beings as an integral part of the landscape, rather than as a species set aside from nature. This orientation may account for Hispanic Americans' greater preference for developed facilities and services in outdoor recreation areas as compared with Anglos. The pattern of ethnic-group differences extends to black-white comparisons as well. African Americans prefer more managed and developed outdoor recreation settings than do whites. African Americans are also more likely to list safety concerns as a factor affecting their park use.

Research on acculturation and recreation suggests that cultural assimilation may play an important role in shaping Hispanic Americans' (and perhaps Asian Americans') outdoor recreation behaviors and styles. In some cases, 
the dominant pattern appears to be one of Anglo-conformity, with ethnic behaviors and styles becoming progressively more Anglo-like as acculturation increases. In other cases, particularly those involving core ethnic values such as familism, the evidence for Anglo-conformity is less conclusive. In part, contradictions in research findings may be due to problems that arise from comparing results of regional household surveys with results from onsite visitor studies and because of differences in the way cultural assimilation is measured (i.e., as generational tenure or language acculturation). In addition, some studies have failed to control for other critical differences between cultural-assimilation groups, such as age, income, and education, that could affect recreation style and participation. Also, it is not clear that assimilation studies can be easily applied (or are even relevant) to the African-American population in the U.S.

When considered as an independent variable, a small amount of research has found that, at least among Mexican Americans, perceptions of assimilation tend to decline with greater levels of assimilation into Anglo-American society. One consequence of this is that there may be major differences in opinions regarding the prevalence of discrimination in recreation areas, depending upon Mexican Americans' level of cultural and structural assimilation.

From an operations standpoint, research on acculturation and its relationship to outdoor recreation style and behavior is important. It may be that some sources of difficulty in the relationships between recreation resource managers and some immigrant groups may be less of an issue in subsequent years as the cultural assimilation of these groups progresses.

Research on the recreation behavior and styles of different ethnic groups has been applied to many practical problems in outdoor recreation, including policy and program development, planning, and day-to-day operations. Because recreation managers and planners are unlikely to be well-informed about the preferences and attitudes of ethnically diverse populations, survey and focus groups can provide valuable insights into the needs of distinctive groups and suggest ways to increase visitation and political support from traditionally underrepresented populations.

The following major gaps in knowledge have been identified in this review:

$a$. There is virtually no information on recreation behavior and styles of minority-group visitors to water-based recreation areas.

$b$. It is unclear how widespread perceptions are of discrimination as a cause of underutilization of recreation areas by minority groups. This is limited systematic work in this area, most work being limited to anecdotal and focus-group work. 
c. Changes in the ethnic composition of visitor populations may be producing displacement and avoidance effects in some recreation areas; no research has been done on where displaced recreationists go as an alternative.

$d$. No research has been found that evaluated the effectiveness of different means of oral or written communication in promoting compliance with resources management rules. Research has been conducted with white populations, showing "communication-based management" to be effective in reducing many rule violations. It is not known whether this effectiveness can be extended to members of ethnic groups. 


\section{Introduction}

Differences in the outdoor recreation behavior of ethnic groups has been the subject of research in the United States for more than 30 years. This report reviews the social science literature describing ethnic and racial differences in recreation and leisure behavior and summarizes the national policy context for that research. The review is divided into nine sections.

- The first section examines demographic trends in the ethnic and racial composition of the U.S., as well as population-growth trends in the nation's nonmetropolitan counties. The purpose is to show how the population of the United States is becoming more ethnically and geographically diverse and to set the stage for the subsequent literature review.

- The second section of the report, "Ethnic Diversity and Public Policy," briefly reviews national ethnic policy as reflected in the statutes and regulations of the United States, including two recent executive orders that are especially relevant to ethnicity, race, and outdoor recreation.

- The report's third section presents a summary of current research programs on ethnicity and recreation in the major Federal recreation resource management agencies. These agencies include the U.S. Department of Agriculture (USDA) Forest Service, the U.S. Department of Interior (USDI) National Park Service, the Bureau of Land Management, the U.S. Fish and Wildlife Service, and the U.S. Army Corps of Engineers.

- The fourth section presents an overview of major research issues in studies of ethnicity and recreation. These include issues of "underparticipation" and "underutilization" by minority groups of outdoor recreation resources, as well as comparative studies of differences in recreation style. This overview also describes the process of cultural assimilation (or acculturation) and its possible effect on recreation behavior and style.

- The next three parts of the report present expanded reviews of the major research issues summarized in the third section. Separate sections are devoted to the literature on underparticipation and 
underutilization, differences in recreation style, and the relationship between cultural assimilation and recreation.

- In the eighth section, the report reviews recent applications of recreation ethnicity research to policy and program development, planning, and operations in Federal and State resource management agencies.

- The report concludes with suggestions for future research based on gaps in the current social science literature. 


\section{Demographic Trends}

\section{Defining Race and Ethnicity}

A major criticism of much research comparing the recreation patterns of different cultural groups is that researchers have interpreted racial differences as ethnic differences, thus confounding these two distinct concepts. Hutchison (1988:18) notes the following:

Ethnicity is usually defined as membership in a subcultural group on the basis of country of origin, language, religion, or cultural traditions different from the dominant society. Race, on the other hand, is based on socially constructed definitions of physical appearances.

Van den Berghe (1976) makes a similar distinction. According to this author, members of an ethnic group share a common cultural tradition (as opposed to racial characteristics) and also have some degree of consciousness of being different from other such groups.

One of the shortcomings of virtually every published study of ethnicity and recreation before the late 1980s was the use of race as an indicator of ethnicity. Although in some cases race and ethnicity covary, this is not true for all ethnic groups. For example, Hispanic Americans can be of any race, although all Hispanic-origin groups share common ethnic roots in their ancestral ties to Spain. Unfortunately, most early national studies of outdoor recreation participation included racial comparisons, but not ethnic comparisons. As a result, national comparative data on recreation behavior often do not include Hispanic Americans as an ethnic category.

The U.S. Census Bureau employs the following five racial/ethnic groupings in its population estimates and projections: "white," "black," "Asian and Pacific Islander (API)," "American Indian, Eskimo, and Aleut (AIEA)," and "Hispanic origin." The first four of these are racial categories, while the last is an ethnic category that includes Hispanics of all racial groups. Thus, the white population figures presented in Census Bureau tables include persons of Hispanic-origin. Similarly, Hispanic population figures presented in these 
same tables include members of black as well as white racial groups. (However, most persons classified as Hispanic are also white.)

\section{Current Ethnic Composition of the United States}

Because the probability of participating in certain types of outdoor recreation activities is affected by a person's race and ethnicity (Dwyer 1994), it is important to be aware of geographic patterns in the nation's ethnic composition, as well as major trends in the growth of different ethnic groups. The ethnic diversity of the U.S. population differs significantly from region to region within the United States, and substantial variation in the growth of different ethnic groups is expected to occur over the next 25 years, with some groups increasing at a much faster rate than others. In general, however, the United States is becoming less white: in 1980, one in five persons in the United States belonged to an ethnic or racial minority; by the year 2020, this proportion is projected to be one in three (U.S. Bureau of the Census 1994). ${ }^{1}$

A major force behind the nation's demographic transformation has been the dramatic increase in the Hispanic-American population. Between 1980 and 1990 the number of Hispanics living in the U.S. grew 53.1 percent, compared to a 9.8 percent increase in the population as a whole. Presently, Hispanic groups constitute the country's second-largest minority after African Americans, but are projected to exceed African Americans in numbers by the second decade of the twenty-first century (U.S. Bureau of the Census 1994). As shown in Table 1, in States bordering on Mexico, Hispanics (mostly Mexican Americans) already substantially surpass African Americans, Asian Americans, and other minority groups in population size.

States outside the Southwest, but with significant Hispanic-origin populations in 1993, included Florida (13.1 percent), New Jersey (10.7 percent), and New York (12.8 percent). Florida's Hispanic population is largely of Cuban origin, while New Jersey's and New York's are mostly Puerto Rican. Only two States in the U.S. had large Asian-American populations in 1993 (including Pacific Islanders). These were California (1.2 percent) and Hawaii (58.2 percent).

Just as the Hispanic-origin populations tend to be concentrated in the southwestern U.S., Table 2 shows that black Americans make up a high percentage of the population in States of the Southeast. Additionally, Table 3 shows that in 1993, substantial black populations also resided in the Great Lakes and Mid-Atlantic States of Delaware, Illinois, Michigan, New Jersey, New York, Ohio, and Pennsylvania.

1 All population projections are from the Bureau of Census "Middle Series" projections. 


\begin{tabular}{|c|c|c|c|c|c|}
\hline \multicolumn{6}{|c|}{$\begin{array}{l}\text { Table } 1 \\
\text { Percent Race/Ethnic Group in Southwestern and Pacific } \\
\text { States - } 1993 \text { Estimates }\end{array}$} \\
\hline & White & Black & API & AIEA & Hispanic \\
\hline Arizona & 88.9 & 3.1 & 2.0 & 6.1 & 20.2 \\
\hline California & 80.1 & 7.7 & 11.2 & 0.9 & 27.3 \\
\hline Colorado & 92.7 & 4.2 & 2.2 & 0.9 & 13.4 \\
\hline Hawaii & 38.5 & 2.8 & 58.2 & 0.5 & 8.1 \\
\hline Nevada & 87.3 & 6.7 & 4.2 & 1.8 & 12.1 \\
\hline New Mexico & 87.4 & 2.0 & 1.3 & 9.4 & 40.0 \\
\hline Oregon & 93.7 & 1.7 & 3.1 & 1.5 & 4.5 \\
\hline Texas & 85.2 & 12.1 & 2.3 & 0.4 & 27.3 \\
\hline Washington & 89.9 & 3.0 & 5.3 & 1.8 & 5.0 \\
\hline \multicolumn{6}{|c|}{$\begin{array}{l}\text { Note: Totals can be obtained by adding White, Black, AIEA, and API. Persons of Hispanic } \\
\text { ethnicity may be of any race, although most are white. AIEA refers to American Indian, } \\
\text { Eskimo, and Aleut. API refers to Asian and Pacific Islander. } \\
\text { Source: U.S. Bureau of the Census, Current Population Reports, P25-1111, Population } \\
\text { Projections for States, by Age, Sex, Race, and Hispanic Origin: } 1993 \text { to 2020, by Paul R. } \\
\text { Campbell, U.S. Government Printing Office, Washington, DC, } 1994 \text {. }\end{array}$} \\
\hline
\end{tabular}

\section{Projected Ethnic Composition of the United States}

In general, the growth of the U.S. population is being fueled by increases in the size of its minority groups. Of the 70 million persons expected to be added to the country's population between 1980 and 2025, nearly 25 million are projected to be Hispanic, 17 million will be black, and persons of other racial and ethnic groups will increase by about 14 million (Murdock et al. 1990). Thus, 78 percent of the growth in the U.S. population between 1980 and 2025 will most likely result from increases in the minority population (Murdock et al. 1990). However, the magnitude of this increase will vary considerably by region.

States projected to add large numbers of Hispanic residents by 2020 include California (17.5 million), Texas (13.3 million), and Illinois (6.2 million). Although Asian and Pacific Islanders will not increase as much, California (9.7 million), New York (1.5 million), and Texas (1.1 million) are expected to see significant growth in these ethnic groups. The Pacific States of Hawaii and Washington will add 876,000 and 858,000 Asians and Pacific Islanders to their populations, respectively. 


\begin{tabular}{|c|c|c|c|c|c|}
\hline \multicolumn{6}{|c|}{$\begin{array}{l}\text { Table } 2 \\
\text { Percent Race/Ethnicity Group in Southeastern States - } 1993 \\
\text { Estimates }\end{array}$} \\
\hline & White & Black & API & AIEA & Hispanic \\
\hline Alabama & 73.6 & 25.3 & 0.7 & 0.4 & 0.6 \\
\hline Arkansas & 82.9 & 15.8 & \begin{tabular}{|l|}
0.7 \\
\end{tabular} & 0.6 & 1.0 \\
\hline Florida & 84.0 & 14.3 & 1.5 & 0.3 & 13.1 \\
\hline Georgia & 71.1 & 27.3 & 1.4 & 0.2 & 1.9 \\
\hline Kentucky & 92.0 & 7.3 & 0.6 & 0.2 & 0.6 \\
\hline Louisiana & 67.1 & 31.2 & 1.2 & 0.4 & 2.4 \\
\hline Maryland & 70.0 & 26.2 & 3.5 & 0.3 & 2.9 \\
\hline Mississippi & 63.4 & 35.7 & 0.6 & 0.3 & 0.6 \\
\hline Missouri & 87.7 & 10.9 & 1.0 & 0.4 & 1.3 \\
\hline North Carolina & 75.5 & 22.2 & 1.1 & 1.2 & 1.3 \\
\hline South Carolina & 68.9 & 30.1 & 0.8 & 0.2 & 1.0 \\
\hline Tennessee & 82.9 & 16.1 & 0.8 & 0.2 & 0.8 \\
\hline Virginia & 77.6 & 19.2 & 3.0 & 0.2 & 2.8 \\
\hline \multicolumn{6}{|c|}{$\begin{array}{l}\text { Note: Totals can be obtained by adding White, Black, AIEA, and API. Persons of Hispanic } \\
\text { ethnicity may be of any race, although most are white. AIEA refers to American Indian, } \\
\text { Eskimo, and Aleut. API refers to Asian and Pacific Islander. } \\
\text { Source: U.S. Bureau of the Census, Current Population Reports, P25-1111, Population } \\
\text { Projections for States, by Age, Sex, Race, and Hispanic Origin: } 1993 \text { to 2020, by Paul R. } \\
\text { Campbell, U.S. Government Printing Office, Washington, DC, } 1994 .\end{array}$} \\
\hline
\end{tabular}

Increases in the African-American population are projected to be much smaller than in the Hispanic population, but larger than among Asian residents. In addition, the black population will continue to be much more geographically dispersed, reflecting the current residence pattern of this group. While States in the Southeast will experience growth in their AfricanAmerican populations, the greatest numerical increases will be in New York (4.0 million), California (3.8 million), and Texas (3.2 million). Several of the Great Lakes States also should see sizable gains in the number of AfricanAmerican residents, including Illinois (2.4 million), Michigan (2.0 million), and Ohio (1.6 million).

Table 4 displays the projected ethnic/racial composition of the southwestern and Pacific States in 2020, while Table 5 presents this information for the southeastern States. Population projections for the Great Lakes and MidAtlantic States are shown in Table 6. 


\begin{tabular}{|c|c|c|c|c|c|}
\hline \multicolumn{6}{|c|}{$\begin{array}{l}\text { Table } 3 \\
\text { Percent Race/Ethnic Group in Great Lakes and Mid-Atlantic } \\
\text { States - } 1993 \text { Estimates }\end{array}$} \\
\hline & White & Black & API & AIEA & Hispanic \\
\hline Delaware & 80.1 & 17.9 & 1.7 & 0.3 & 2.9 \\
\hline Illinois & 81.5 & 15.3 & 3.0 & 0.2 & 8.7 \\
\hline Indiana & 90.9 & 8.0 & 0.8 & 0.2 & 2.0 \\
\hline Michigan & 83.6 & 14.5 & 1.3 & 0.6 & 2.4 \\
\hline New Jersey & 81.4 & 14.3 & 4.1 & 0.2 & 10.7 \\
\hline New York & 77.7 & 17.6 & 4.4 & 0.3 & 12.8 \\
\hline Ohio & 87.8 & 11.0 & 1.0 & 0.2 & 1.4 \\
\hline Pennsylvania & 89.0 & 9.5 & 1.4 & 0.1 & 2.3 \\
\hline Wisconsin & 92.4 & 5.4 & 1.3 & 0.9 & 2.1 \\
\hline \multicolumn{6}{|c|}{$\begin{array}{l}\text { Note: Totals can be obtained by adding White, Black, AIEA, and API. Persons of Hispanic } \\
\text { ethnicity may be of any race, although most are white. AIEA refers to American Indian, } \\
\text { Eskimo, and Aleut. API refers to Asian and Pacific Islander. } \\
\text { Source: U.S. Bureau of the Census, Current Population Reports, P25-1111, Population } \\
\text { Projections for States, by Age, Sex, Race, and Hispanic Origin: } 1993 \text { to 2020, by Paul R. } \\
\text { Campbell, U.S. Government Printing Office, Washington, DC, } 1994 \text {. }\end{array}$} \\
\hline
\end{tabular}

As seen in Table 4, with the exception of Hawaii, the white population is expected to decline as a percentage of the total in each of the southwestern and Pacific States. In contrast, the percentage of Hispanic residents should increase considerably in all southwestern States, while California should also experience major growth in the proportion of its Asian-American population. However, changes in the percentage of each State's population in the "black" and "AIEA" categories are expected to be much smaller.

In New Mexico, a majority of the residents (55.4 percent) are expected to be Hispanic by the year 2020 . Texas is projected to have approximately equal proportions of Hispanic and Anglo residents. ${ }^{1}$

Table 5 shows that, with the exception of Florida, which has been heavily influenced by Cuban immigration into the southern part of the State, African Americans will continue to be the dominant racial minority in the Southeast. In fact, compared with the Southwest, ethnic change in the southeastern States is expected to be relatively slow-paced, reflecting the generally slower growth

1 Note that percentage changes do not necessarily reflect proportionate changes in numbers. For example, even though the white population in California is shown to decline by 9.1 percent by 2020 , it will still increase in numbers by almost nine million. Even so, much of this increase will be in the Hispanic-origin population, the majority of whom are classified as "white." 


\begin{tabular}{|c|c|c|c|c|c|}
\hline & White & Black & API & AIEA & Hispanic \\
\hline Arizona & $85.0(-3.9)$ & $2.7(-0.4)$ & $5.0(+3.0)$ & $7.3(+1.2)$ & $31.7(+11.5)$ \\
\hline California & $71.0(-9.1)$ & $8.0(+0.3)$ & $20.2(+9.0)$ & $0.8(-0.1)$ & $36.5(+9.2)$ \\
\hline Colorado & $90.1(-2.6)$ & $4.6(+0.4)$ & $4.4(+2.2)$ & $0.8(-0.1)$ & $20.0(+7.0)$ \\
\hline Hawaii & $47.9(+9.4)$ & $3.2(+0.4)$ & $48.2(-10.0)$ & $0.7(+0.2)$ & $13.7(+5.6)$ \\
\hline Nevada & $81.3(-6.0)$ & $7.7(+1.0)$ & $9.2(+5.0)$ & $1.8(+0.0)$ & $26.1(+14.0)$ \\
\hline Oregon & $89.1(-4.6)$ & $1.9(+0.2)$ & $7.5(+4.4)$ & $1.6(+0.1)$ & $8.1(+3.6)$ \\
\hline New Mexico & $82.7(-4.7)$ & $1.7(-0.3)$ & $3.3(+2.0)$ & $12.3(+2.9)$ & $55.4(+15.4)$ \\
\hline Texas & $82.9(-2.3)$ & $12.6(+0.5)$ & $4.2(+1.9)$ & $0.3(-0.1)$ & $40.3(+13.0)$ \\
\hline Washington & $84.8(-5.1)$ & $2.6(-0.4)$ & $10.8(+5.5)$ & $1.9(+0.1)$ & $8.9(+3.9)$ \\
\hline \multicolumn{6}{|c|}{$\begin{array}{l}\text { Note: Totals can be obtained by adding White, Black, AIEA, and API. Persons of Hispanic } \\
\text { ethnicity may be of any race, although most are white. AIEA refers to American Indian, } \\
\text { Eskimo, and Aleut. API refers to Asian and Pacific Islander. } \\
\text { Source: U.S. Bureau of the Census, Current Population Reports, P25-1111, Population } \\
\text { Projections for States, by Age, Sex, Race, and Hispanic Origin: } 1993 \text { to 2020, by Paul R. } \\
\text { Campbell, U.S. Government Printing Office, Washington, DC, } 1994 \text {. }\end{array}$} \\
\hline
\end{tabular}

of the Anglo and black populations in the U.S. compared with the Hispanic population. Even so, as a percentage of all residents, ethnic and racial minorities will gradually increase across the South, with the most dramatic gains occurring in the border state of Maryland.

As in other regions of the country, the Great Lakes and Mid-Atlantic States will see proportionate declines in their white populations into the next century (Table 6). Percentage-wise, the greatest increases in the black population are expected to occur in Delaware and Michigan. Hispanic residents will make up significant proportions of the total population in Illinois, New Jersey, and New York. Even so, in each of the States shown in Table 6, African Americans will continue to be the dominant minority group.

\section{Population Growth in Nonmetropolitan Areas}

In a reversal of the trend of the 1980s, nonmetropolitan areas of the United States experienced widespread population growth during the 1990s (Johnson and Beale 1994). Although the nation's 834 metro counties continued to grow at the fastest rate between 1980 and 1992 (11.6 percent), the 2,277 counties classified as nonmetropolitan also experienced both natural increases in population and net in-migration. This pattern of growth was most pronounced in 


\begin{tabular}{|c|c|c|c|c|c|}
\hline \multicolumn{6}{|c|}{$\begin{array}{l}\text { Table } 5 \\
\text { Percent Race/Ethnic Group in Southeastern States - } 2020 \text { Projec- } \\
\text { tions (Percent change from } 1993 \text { estimates are shown in } \\
\text { parentheses) }\end{array}$} \\
\hline & White & Black & API & AIEA & Hispanic \\
\hline Alabama & $72.0(-1.6)$ & $26.0(+0.7)$ & $1.6(+0.9)$ & $0.4(+0.0)$ & $1.2(+0.6)$ \\
\hline Arkansas & $83.1(+0.2)$ & $14.4(-1.4)$ & $1.9(+1.2)$ & $0.7(+0.1)$ & $1.9(+0.9)$ \\
\hline Florida & $78.9(-5.1)$ & $17.9(+3.6)$ & $3.0(+1.5)$ & $0.2(-0.1)$ & $21.5(+8.4)$ \\
\hline Georgia & $66.9(-4.2)$ & $30.2(+2.9)$ & $2.7(+0.7)$ & $0.1(-0.1)$ & $3.2(+1.3)$ \\
\hline Kentucky & $89.7(-2.3)$ & $9.0(+1.7)$ & $1.2(+0.6)$ & $0.1(-0.1)$ & $1.0(+0.4)$ \\
\hline Louisiana & $63.9(-3.2)$ & $32.5(+1.3)$ & $3.1(+1.9)$ & $0.4(+0.0)$ & $3.6(+1.2)$ \\
\hline Maryland & $59.6(-10.4)$ & $32.6(+6.4)$ & $7.5(+4.0)$ & $0.2(-0.1)$ & $5.0(+2.1)$ \\
\hline Mississippi & $63.1(-0.3)$ & $35.2(-0.5)$ & $1.3(+0.7)$ & $0.3(+0.0)$ & $1.0(+0.4)$ \\
\hline Missouri & $85.5(-2.2)$ & $11.9(+1.0)$ & $2.3(+1.3)$ & $0.4(+0.0)$ & $2.2(+0.9)$ \\
\hline North Carolina & $72.3(-3.2)$ & $23.5(+1.3)$ & $2.9(+1.8)$ & $1.3(+0.1)$ & $2.4(+1.1)$ \\
\hline South Carolina & $66.5(-2.4)$ & $31.7(+1.6)$ & $1.6(+0.8)$ & $0.2(+0.0)$ & $1.8(+0.8)$ \\
\hline Tennessee & $80.6(-2.3)$ & $17.5(+1.4)$ & $1.7(+0.9)$ & $0.2(+0.0)$ & $1.3(+0.5)$ \\
\hline Virginia & $72.5(-5.1)$ & $21.6(+2.4)$ & $5.7(-2.7)$ & $0.2(+0.0)$ & $4.7(+1.9)$ \\
\hline \multicolumn{6}{|c|}{$\begin{array}{l}\text { Note: Totals can be obtained by adding White, Black, AIEA, and API. Persons of Hispanic } \\
\text { ethnicity may be of any race, although most are white. AIEA refers to American Indian, } \\
\text { Eskimo, and Aleut. API refers to Asian and Pacific Islander. } \\
\text { Source: U.S. Bureau of the Census, Current Population Reports, P25-1111, Population } \\
\text { Projections for States, by Age, Sex, Race, and Hispanic Origin: } 1993 \text { to 2020, by Paul R. } \\
\text { Campbell, U.S. Government Printing Office, Washington, DC, } 1994 \text {. }\end{array}$} \\
\hline
\end{tabular}

counties adjacent to metro counties (6.3 percent), but also occurred in nonadjacent counties as well (1.5 percent).

Table 7 shows population growth in different types of nonmetropolitan counties in the early 1990s, based on a county's socioeconomic characteristics (Johnson and Beale 1994). The nonmetro counties experiencing the highest rates of growth between 1990 and 1992 were those that were centers of recreation or destinations for retirement-age migrants (3.7 and 3.6 percent, respectively). ${ }^{1}$ Moreover, in contrast to all other types of nonmetro counties,

1 In the study cited, nonmetro counties designated as "centers of recreation" were identified using a composite index based on per capita in-county expenditures on hotels, motels, trailering parks, and camps, in addition to county-level measures of employment in entertainment and recreation services; percentage of personal income from earnings in recreation, amusements, hotels and other lodging; and percentage of housing units held for seasonal, recreational, or occasional use. 


\begin{tabular}{|c|c|c|c|c|c|}
\hline \multicolumn{6}{|c|}{$\begin{array}{l}\text { Table } 6 \\
\text { Percent Race/Ethnic Group in Great Lakes and Mid-Atlantic } \\
\text { States - } 2020 \text { Projections (Percent change from } 1993 \text { estimates } \\
\text { are shown in parentheses) }\end{array}$} \\
\hline & White & Black & API & AIEA & Hispanic \\
\hline Delaware & $70.7(-9.4)$ & $24.7(+6.8)$ & $4.2(+2.5)$ & $0.3(+0.0)$ & $5.9(+3.0)$ \\
\hline Illinois & $75.2(-6.3)$ & $18.4(+3.1)$ & $6.2(+3.2)$ & $0.2(+0.0)$ & $15.7(+7.0)$ \\
\hline Indiana & $87.7(-3.2)$ & $10.0(+2.0)$ & $2.0(+1.2)$ & $0.2(+0.0)$ & $4.0(+2.0)$ \\
\hline Michigan & $77.0(-6.6)$ & $19.2(+4.7)$ & $3.2(+1.9)$ & $0.6(+0.0)$ & $4.6(+2.2)$ \\
\hline New Jersey & $73.5(-7.9)$ & $18.2(+3.9)$ & $8.2(+4.1)$ & $0.1(-0.1)$ & $17.0(+6.3)$ \\
\hline New York & $70.6(-7.1)$ & $21.1(+3.5)$ & $8.1(+3.7)$ & $0.2(-0.1)$ & $15.9(+3.1)$ \\
\hline Ohio & $83.8(-4.0)$ & $13.8(+2.8)$ & $2.2(+1.2)$ & $0.2(+0.0)$ & $2.9(+1.5)$ \\
\hline Pennsylvania & $85: 4(-3.6)$ & $11.4(+1.9)$ & $3.2(+1.8)$ & $0.1(+0.0)$ & $4.9(+2.6)$ \\
\hline Wisconsin & $87.8(-4.6)$ & $8.0(+2.6)$ & $3.3(+2.0)$ & $0.9(+0.0)$ & $4.61+2.5$ \\
\hline \multicolumn{6}{|c|}{$\begin{array}{l}\text { Note: Totals can be obtained by adding White, Black, AIEA, and API. Persons of Hispanic } \\
\text { ethnicity may be of any race, although most are white. AIEA refers to American Indian, } \\
\text { Eskimo, and Aleut. API refers to Asian and Pacific Islander. } \\
\text { Source: U.S. Bureau of the Census, Current Population Reports, P25-1111, Population } \\
\text { Projections for States, by Age, Sex, Race, and Hispanic Origin: } 1993 \text { to 2020, by Paul R. } \\
\text { Campbell, U.S. Government Printing Office, Washington, DC, } 1994 \text {. }\end{array}$} \\
\hline
\end{tabular}

most of the population growth in recreation and retirement counties resulted from increases in net in-migration from other areas, rather than natural increases in the resident population. Because many U.S. Army Corps of Engineers (CE) water resource projects are located outside (but close to) metropolitan areas, this trend in all likelihood signals an impending increase in demand for recreation at these projects. (No published analyses of the ethnic dimensions of nonmetropolitan population growth were found.) This increase in demand is further enhanced at the numerous $\mathrm{CE}$ projects located in nonmetro counties either in close proximity to metropolitan areas or easily accessible by interstate highways.

\section{Summary}

The demographic profile of the United States is changing toward a more ethnically and geographically diverse population. Although Asian-origin and African-American groups should increase significantly in numbers over the next 25 years, the ethnic transformation of the U.S. is being driven primarily by the rapid growth of its Hispanic population. This growth is being experienced in a relatively restricted geographic region composed of the States adjacent to or near the U.S.-Mexico border. However, other pockets of strong 


\begin{tabular}{|c|c|c|c|c|c|c|c|}
\hline \multicolumn{8}{|c|}{$\begin{array}{l}\text { Table } 7 \\
\text { Population Change, Net Migration, and Natural Increase in } \\
\text { Nonmetropolitan Counties by Selected Variables - } 1990 \text { to } 1992\end{array}$} \\
\hline & \multirow[b]{2}{*}{$\mathbf{N}$} & \multicolumn{2}{|c|}{ Population Change } & \multicolumn{2}{|c|}{ Net Migration } & \multicolumn{2}{|c|}{ Natural Increase } \\
\hline & & $\begin{array}{l}\text { Percent } \\
\text { Change }\end{array}$ & $\begin{array}{l}\text { Percent } \\
\text { Growing }\end{array}$ & $\begin{array}{l}\text { Percent } \\
\text { Change }\end{array}$ & $\begin{array}{l}\text { Percent } \\
\text { Growing }\end{array}$ & $\begin{array}{l}\text { Percent } \\
\text { Change }\end{array}$ & $\begin{array}{l}\text { Percent } \\
\text { Growing }\end{array}$ \\
\hline Recreational & 283 & 3.7 & 88 & 2.7 & 79 & 1.0 & 82 \\
\hline Retirement & 443 & 3.6 & 87 & 2.7 & 82 & 0.9 & 76 \\
\hline Manufacturing & 513 & 1.7 & 82 & 0.7 & 62 & 1.0 & 95 \\
\hline Government & 323 & 2.3 & 74 & 0.7 & 60 & 1.6 & 85 \\
\hline Poverty & 236 & 1.6 & 73 & 0.6 & 57 & 1.0 & 89 \\
\hline Mining & 122 & 0.9 & 59 & -0.1 & 44 & 1.1 & 86 \\
\hline Low density & 387 & 1.1 & 41 & -0.2 & 32 & 1.3 & 68 \\
\hline Farming & 510 & 0.6 & 35 & -0.2 & 28 & 0.8 & 63 \\
\hline Total nonmetro & 2,227 & 1.7 & 64 & 0.7 & 51 & 1.0 & 80 \\
\hline \multicolumn{8}{|c|}{$\begin{array}{l}\text { Notes: Country types are not mutually exclusive. Recreational countries defined according } \\
\text { to criteria described in text. Farm, manufacturing, mining, and Government counties as of } \\
1986 \text { by Hady and Ross (1990). Retirement destination and poverty counties } 1979 \text { as } \\
\text { defined by Hady and Ross (1990). Low-density counties had fewer than six persons per } \\
\text { square mile in } 1990 \text {. Percent change is aggregate change for all cases in a category. } \\
\text { Source: Modified from Johnson and Beale (1994). }\end{array}$} \\
\hline
\end{tabular}

Hispanic growth are occurring in south Florida, the industrial States of the Northeast, and in Illinois.

Growth in the population of nonmetropolitan counties is also occurring, reversing a decade of decline during the 1980s. An increase in net in-migration to counties with recreation-dominated economies and to rural retirement destinations is one factor underlying nonmetropolitan growth in the U.S. Even so, the greatest population increases continue to be in metropolitan counties. 


\section{Ethnic Diversity and Public Policy}

National policies concerning ethnic diversity fall into two broad categories (Marger 1985; McLemore 1991). "Pluralism" describes a continuum of policies that, to varying degrees, encourage retention of ethnic differences within a single political system. In contrast, "assimilation" is a policy that seeks to reduce or eliminate cultural distinctions within societies.

Various types of assimilation have been described. Gordon's (1964) taxonomy listed seven assimilation subprocesses. These were (a) cultural assimilation, (b) structural assimilation, (c) marital assimilation, (d) identificational assimilation, (e) attitude receptional assimilation, (f) behavioral receptional assimilation, and (g) civic assimilation. Other authors"(e.g., Keefe and Padilla 1987; McLemore 1991) prefer to focus on fewer categories. Typically these are cultural assimilation (also called "acculturation") and structural assimilation.

Cultural assimilation refers to an ethnic minority's acceptance of the dominant cultural pattern of the host society (e.g., language, religion, diet, dress, and child-rearing practices). In contrast, structural assimilation refers to the social, economic, and political integration of ethnic minorities into mainstream society (Marger 1985). The aim of the latter policy is to guarantee equal access of all groups to society's major institutions, such as education, the economy, and Government (including public recreation areas).

The U.S. clearly has a policy of structural assimilation with respect to its ethnic minorities. This is expressed in such national mandates as public school integration, bilingual education, equal-opportunity employment, and voting rights legislation. It is also expressed in constitutional, statutory and regulatory guarantees of fundamental human rights to all residents of the U.S., regardless of race, cultural background, or religious belief. Despite this, throughout the history of the United States, many people (perhaps the majority) have viewed Anglo-American Protestantism as the "semi-official" version of American life (McLemore 1991). In recent years, this has led to political movements nationally and in many States to adopt English as an official language of Government and to promote Christian prayer in public 
schools, both of which are consistent with a policy of cultural assimilation. ${ }^{1}$ In addition, recent attempts in Congress and in many States to restrict or deny social services to immigrants (both legal and illegal) challenge even the longstanding policy of structural assimilation. To further complicate matters, it is not at all clear, as Gordon pointed out in 1964, that all ethnic groups in the U.S. want to be completely acculturated, even though they may desire full participation in society's institutional structure.

Nevertheless, because the U.S. has an official policy of structural assimilation (at least with regard to its U.S.-born citizens), and because equal access to publicly provided recreation areas constitutes one aspect of this policy, ensuring such access is a legitimate public-policy concern. The equitable treatment of all persons served by Federal agencies is the subject of two recent presidential executive orders.

\section{Executive Order 12862: Setting Customer Service Standards}

On September 11, 1993, President Clinton issued Executive Order 12862, "Setting Customer Service Standards." This order directed Federal agencies to carry out certain activities to conform to the requirements and principles of the National Performance Review as described in P.L. 103-62, "Government Performance and Results Act of 1993." Under terms of the executive order, Federal agencies are to (a) identify the customers who are, or should be, served by the agency and (b) survey customers to determine the kind and quality of services they want and their level of satisfaction with existing services. The purpose of developing information on customer satisfaction is to set service standards that will allow Federal agencies to "provide service to the public that matches or exceeds the best service available in the private sector." Furthermore, customer satisfaction is to be used to judge the performance of agency management and to make resource allocations.

The reference in the executive order to customers who should be served, in addition to those who are served, suggests that agencies such as the CE should not only be concerned with current recreational users of Corps projects, but with those who fall within the agency's service mandate, but are not reached. This includes many members of ethnic and racial minority groups.

\footnotetext{
1 As a recent example of this, in February 1995, H.R. 1005, the National Language Act of 1995, was introduced into the U.S. House of Representatives of the 104th Congress. If enacted, this law would make English the official language of the United States Government, repeal the Bilingual Education Act (20 U.S.C. 3281 et seq.) and repeal the bilingual election requirements of Section 203 of the Voting Rights Act of 1965 (42 U.S.C. 1973aa-1a). Thus, what has historically been the central sociological fact of U.S. assimilation policy, i.e., the requirement for structural assimilation without cultural assimilation, may be eroding.
} 


\section{Executive Order 12898: Federal Actions to Address Environmental Justice in Minority Popula- tions and Low-Income Populations}

This "environmental-justice" executive order was issued by President Clinton on February 11, 1994, and was accompanied by a memorandum from the President to the heads of all Federal departments and agencies. The effect of Federal actions on minority populations are explicitly described, together with actions that are to be taken to address these concerns. Although much of the executive order deals with human-health issues or with environmental issues directly affecting human health, Federal agencies are also directed to "identify differential patterns of consumption of natural resources among minority populations and low-income populations" and to ensure that programs, policies, or activities that substantially affect human health or the environment (including, it must be supposed, outdoor recreation operations) do not exclude persons from receiving the benefits of such programs as a result of race, color, or national origin. Furthermore, each Federal agency is ordered to, whenever practicable, collect, maintain, and analyze information on the race and national origin of residents of areas surrounding Federal facilities or sites that have substantial environmental, human-health, or economic effects on nearby populations. Finally, in Section 4-4, agencies are directed to collect, when appropriate, data on the consumption patterns of populations who principally use fish and/or wildlife for subsistence in order to more effectively protect these populations from the possibility of pollutantbearing fish and game.

There is a substantial amount of research describing the physiological, psychological, social, and economic effects of outdoor recreation on individuals and on recreation-dependent communities (Driver, Brown, and Peterson 1991; Watson and Cordell 1990). Some of these effects, such as cardiovascular fitness and psychological stress reduction, have clear relationships to human health (Froelicher and Froelicher 1991; Ulrich, Dimberg, and Driver 1991). In other cases, the provision of outdoor recreation opportunities, such as those managed by the $\mathrm{CE}$, frequently produces significant impacts on the natural environment, as well as on surrounding populations (Burdge and Opryszek 1981; Napier 1981). These may include modifications in traditional land uses and associated livelihoods (Hales 1991), changes in the perceived quality of life (Long, Perdue, and Allen 1990), income and employment impacts (Gramann 1983; Watson and Cordell 1990), shifts in property values (Poudel 1979), and fiscal effects in the form of changes in tax revenues and expenditures by local governments to provide services (Siegel and Leuthold 1992). Therefore, it is reasonable to assume that CE programs and policies related to outdoor recreation, including those affecting ethnic use and nonuse of $\mathrm{CE}$ projects, fall under the purview of both executive orders. 


\section{Summary}

The U.S. policy of structural assimilation guarantees the opportunity for equal access by all U.S. residents to publicly funded or managed recreation areas, including those operated by the U.S. Army Corps of Engineers. Historically, some ethnic and racial groups in the United States have made less use of these areas than others. This may mean that Federal actions to date have met with limited success in ensuring the opportunity for equal access by minority groups to these types of public facilities. Two recent executive orders underscore the commitment of the Federal government to providing quality service and equitable treatment to all ethnic and racial groups in the United States. 


\section{Ethnicity Research by Fed- eral Recreation Resource Management Agencies}

\section{USDA Forest Service}

In the U.S. Forest Service, ethnicity-related research dealing with forest recreation is centered in three Forest Service "research work units." Riverside, CA, is the location of the "Wildland Recreation and Urban Culture Project" of the Pacific Southwest Forest and Range Experiment Station. Research sponsored by this unit has focused on identifying and contrasting Anglo and Hispanic recreation patterns in the southwestern U.S., primarily at the interface of national forests and large metropolitan areas, such as Los Angeles, San Diego, and Phoenix (Ewert, Chavez, and Magill 1993). It also has examined environmental values and perceptions of Anglo and Hispanic Americans. This research has usually been conducted at recreation areas, although some regional household surveys also have been carried out. The latter have permitted the identification of non-users as well as users of Forest Service lands, together with the reasons for their nonuse.

A research work unit titled "Managing Forest Environments for Urban Populations" is located in Evanston, IL, as part of the North Central Forest Experiment Station. The research of this unit has focused on the recreation behavior and environmental perceptions of racial and ethnic minorities in urban settings (Hutchison 1987). This focus on recreation within urban areas distinguishes it from the Riverside research work unit. The Evanston unit recently funded a study of first-nation (i.e., aboriginal) perspectives on national parks in Canada, one of the very few recreation studies to deal with native Americans.

The third Forest Service work unit to include ethnicity and recreation in its research mission is the "Outdoor Recreation and Wilderness Assessment Group," located in Athens, GA. The primary emphasis of this group has been on national studies of recreation "customers" and the projected demand for outdoor recreation (Cordell et al. 1990). Although ethnicity has not been a major focus of this unit, racial data are usually collected in its surveys. The 
unit spearheaded the Public Area Recreation Visitor Survey in the 1980s, which later evolved into the current Customer Survey. Currently, the group is planning the National Survey on Recreation and the Environment, the first nationwide household survey of recreation behavior by a Federal agency in more than a decade. The Athens work unit also funds a limited number of cooperative research agreements with university partners that deal specifically with ethnicity and recreation.

\section{USDI National Park Service}

The research efforts of the National Park Service (NPS) are much less centralized than those of the Forest Service and deal almost exclusively with surveys of visitors to national parks. One exception was the 1982-1983 Nationwide Recreation Survey (USDI National Park Service 1986), which included race variables (but not ethnicity variables) in its data set. This was the last recreation survey of national scope conducted in the U.S. prior to the planned National Survey on Recreation and the Environment. Under NPS cooperative agreements with university partners, scores of park-specific visitor surveys have been conducted. However, with few exceptions (e.g., Snow 1989), these have not focused on ethnicity-related issues, even though ethnicity data may have been collected. One reason for this is that NPS units, except for some urban units and African-American heritage sites, do not normally attract ethnically diverse visitor populations.

The National Park Service operates its own national survey unit, based at the University of Idaho. This unit, known as the "Visitor Services Project," conducts short visitor surveys in 10 NPS units each year. With rare exceptions, race and ethnicity data are not collected. The Visitor Services Project is the National Park Service's response to the requirement to assess customer satisfaction under the National Performance Review and Executive Order 12862. (However, it predates these Federal mandates by several years.)

Currently, NPS is conducting an assessment of the priorities and institutional structure for a possible national-level social science program. Beginning June 1, 1995, NPS had a chief sociologist, whose task is to make final recommendations for social science based on the current assessment. Such a need was perceived by the agency following the transfer of most of its research scientists to the National Biological Service. Research on ethnic diversity in park visitation has been tentatively identified as a priority of the proposed program.

\section{USDI Bureau of Land Management}

The Bureau of Land Management (BLM) did not receive broad authority to manage recreation on lands under its jurisdiction until passage of the Federal Land Policy and Management Act of 1976. Since that time, BLM has carried 
out only limited research on recreational use of its areas. In cooperation with the Wildland Recreation and Urban Culture project of the USDA Forest Service, BLM has conducted visitor surveys on some of its sites in southern California. These studies have focused on differences in recreation behavior and facility preferences between Hispanic Americans and Anglo Americans (Baas, Ewert, and Chavez 1993; Chavez, Baas, and Winter 1993).

\section{U.S. Fish and Wildlife Service}

Social science research in the U.S. Fish and Wildlife Service (USFWS) is limited almost exclusively to the National Survey of Fishing, Hunting, and Wildlife Associated Recreation, a household survey conducted every 5 years (U.S. Fish and Wildlife Service 1988). The most recent of these surveys was completed in 1990, although one is due to be conducted in 1995. As with the 1982-83 nationwide recreation study, the USFWS survey has typically collected data on race, but not on ethnicity. Despite this limitation, the USFWS survey is valuable because it is the only accessible longitudinal research on recreation behavior in the United States. For this reason, it is especially useful in describing changing trends in fisheries-related and wildlife-related recreation behavior over time.

The U.S. Fish and Wildlife Service occasionally cooperates in social science research funded by other agencies in which wildlife refuges serve as research locations. One example is a survey of residents' perceptions of the Lower Rio Grande Valley National Wildlife Refuge in south Texas. This study examined differences between Anglos and Hispanics in their attitudes toward the refuge, as well as differences in the general environmental values held by these two ethnic groups (Gramann and Saenz 1995).

\section{U.S. Army Corps of Engineers}

Recreation research in the CE is primarily conducted through the Natural Resources Division, U.S. Army Engineer Waterways Experiment Station (WES), Vicksburg, MS. Recreation research is conducted under the Natural Resources Research Program (NRRP) at WES, and assistance and technology transfer of research results is conducted through the Natural Resources Technical Support Program by WES. Usually in the form of surveys of recreational visitors, recreation research by the $C E$ tends to be national in scope, rather than being restricted to a single water resource project. Natural resources research tends to be driven more by the expressed needs of managers and staff in the field than is the case with other Federal resource management agencies. Within the Corps, recreation research has not had an explicit

focus on ethnicity until the initiation of the Ethnic Culture and Recreation Use work unit under the NRRP. Despite this, race variables are sometimes included in the CE surveys (e.g., Reiling, McCarville, and White 1994), although they have not been analyzed extensively. In addition to research at 
WES, the CE Institute for Water Resources at Alexandria, VA, performs

policy and economic studies for the $\mathrm{CE}$, often related to recreation and social aspects of water resources.

\section{Summary}

Of the major Federal recreation resource management agencies, only the USDA Forest Service has an institutionalized research focus that explicitly addresses management and social science issues pertaining to ethnicity, race, and outdoor recreation. Other agencies often collect data on the ethnicity or race of visitors, but this is rarely the primary purpose of their research.

Consequently, analyses of these data have been limited. The initiation of the CE work unit on "Ethnic Culture and Corps Recreation Participation" adds needed breadth to this research, as well as diversity to the types of areas and activities examined. 


\section{Overview of Major Research Themes in Ethnicity, Race, and Outdoor Recreation}

This section summarizes several research themes that are included under the general topic of ethnicity, race, and outdoor recreation. Each of these themes represents a somewhat different approach to comparing the recreation patterns of ethnic and racial groups. A more detailed review of research on these themes is included in subsequent sections of this report.

\section{Underparticipation and Underutilization}

In the 1960s and 1970s, a major issue in national recreation research and policy concerned minority-group "underparticipation" in wildland recreation activities. Early studies of participants and non-participants showed that a smaller proportion of blacks took part in many types of outdoor recreation than did whites. This concern also extended to the underutilization of some types of recreation areas, such as rural national parks and forests ${ }^{1}$ (Bultena and Field 1978). The creation of the nation's first urban national recreation areas in New York and San Francisco in 1972 was motivated in part by the desire to reach a constituency of less-mobile urban residents (often members of minority groups) who had been largely inaccessible to agencies providing wildland activities (Wellman 1987).

Although underparticipation certainly has not disappeared as a policy issue, research indicates that it may be less relevant in the case of some ethnic groups, at least in selected regions of the country (Gramann, Floyd, and Ewert 1992). For example, many national forests and BLM areas in the Southwest receive heavy recreational use from Hispanic Americans (Chavez and Winter 1993; Chavez, Baas, and Winter 1993; Irwin, Gartner, and Phelps

1 It is ironic and also indicative of the ethnocentrism of the underutilization studies that the issue was not defined as one of white "overutilization" of increasingly crowded wildland recreation areas. 
1990). In such areas, recreation managers have focused on problems arising from differences in styles of recreational use between ethnic groups, rather than on underutilization (Dennis and Magill 1991).

\section{Outdoor Recreation Style}

Most studies of style differences in outdoor recreation have compared Anglo Americans with Hispanic Americans. As defined by Gramann, Floyd, and Ewert (1992), "style" is the unique quality of recreation behavior that arises from variations between ethnic groups in group size, participation motives, spoken language, and attitudes towards natural resources, including facility-development preferences. The concern with ethnic variation in recreation style frequently reflects concerns on the part of resource managers that the behaviors of some groups may result in inferior recreation experiences, facility damage, and resource degradation. In general, most administrators and staff in U.S. resource management agencies are Anglo Americans (Adams and Moreno 1994). These individuals not only receive a distinctive biocentric training in the natural sciences that sets them apart from many of their recreational users, but they inherit a set of cultural values that further separates them from the ethnic minorities in their user populations (Dustin, Knopf, and Fox 1993). Moreover, even in instances where managers and ethnically diverse user groups share certain fundamental values (e.g., the appreciation of the out-of-doors), visitors may not express these values in ways that managers believe are appropriate.

\section{Acculturation and Recreation}

A major criticism of many recreation studies is that they have treated ethnic and racial groups as culturally homogeneous blocs (Gramann and Floyd 1991; Hutchison 1988). This is especially problematic in the case of Hispanic Americans and Asian Americans, who represent more than a score of different national-origin groups. In addition, even national-origin subgroups, such as Mexican Americans, can be internally differentiated along another dimension that has special relevance to cultural characteristics: number of generations

removed from Mexico. Research has shown that the more generations Mexican Americans can trace back their U.S. ancestry, the greater their degree of assimilation into Anglo culture (Keefe and Padilla 1987). Further, because Mexican immigration to the U.S. is an ongoing phenomenon, the dynamics of acculturation, together with the cultural heterogeneity it produces, will continue to result in an ethnically diverse Mexican-American population. Thus, for many ethnic populations, the assumption of cultural sameness with a group is untenable. This practice presupposes cultural homogeneity within an ethnic bloc when, in reality, there may be considerable diversity because of differences in degree of acculturation. Moreover, the extent of acculturation has important consequences for outdoor recreation behavior. In some cases research has shown that the greater the level of cultural assimilation, the more 
"Anglo-like" some recreation behaviors become. Level of assimilation has also been shown to affect minority-group members' perceptions of discrimination in outdoor recreation settings.

\section{Summary}

Research on ethnicity and recreation centered in its early years on differences between blacks and whites in recreation behavior and visitation patterns. Although some studies were site-specific, others were communitywide, regional, or even national surveys. These allowed investigation not only of visitors, but of nonvisitors and the reasons for their nonuse, which in some cases had ethnic and racial associations.

Studies of recreation behavior have been supplemented in recent years with studies of ethnic differences in recreation style. In large part, this has been due to the rapid growth of the nation's Hispanic population. The increasing prominence of Hispanic visitors to recreation sites in southwestern states has also led to studies of the effect of cultural assimilation on recreation behavior. This research has attempted to answer the general question, "With increasing assimilation do Hispanics become more Anglo-like in their leisure behaviors and styles?"

Less prominent in research on ethnicity and leisure to date have been studies of the recreation behavior and styles of Asian Americans and native Americans.

More detailed discussions of these issues are presented below. 


\section{Research on Underparticipa- tion and Underutilization}

\section{Marginality and Ethnicity Hypotheses}

As noted in the introduction, differences between ethnic groups in outdoor recreation behavior and visitation patterns have been the subject of investigation for over 30 years. Early studies by the Outdoor Recreation Resources Review Commission (Mueller and Guerin 1962) documented variation between African Americans and whites in both rural and urban recreation participation. In general, black minorities were found to have lower participation rates than whites. This was attributed to the lower socioeconomic position of African Americans in a white-dominated society. However, it was also found that when socioeconomic variables were controlled, participation differences between the two racial groups persisted, suggesting that subcultural preferences also were important in explaining variation in recreation behavior. These findings led to the development of two contrasting explanations for the effect of race and ethnicity on outdoor recreation participation.

The first explanation has come to be known as the marginality hypothesis. This hypothesis states that the "underparticipation" of blacks in outdoor recreation results primarily from limited economic resources, which in turn are a function of historical patterns of discrimination (Washburne 1978). In other words, the marginal position of African Americans with respect to society's major institutions (e.g., the economy, education, and government) negatively affects their educational levels and disposable income, which in turn is reflected in reduced participation in some types of outdoor recreation activities.

The second explanation is known as the ethnicity hypothesis. This hypothesis states that minority underparticipation results from culturally based differences between ethnic groups in value systems, norms, and leisure socialization patterns (Washburne 1978). According to this view, these cultural forces, rather than socioeconomic factors, are more significant in explaining differences between blacks and whites in recreation behavior. 
Floyd (1991) points out that the marginality and ethnicity hypotheses suggest very different public policy responses in the provision of outdoor recreation opportunities. Because the marginality hypothesis assumes that the majority and minority groups have the same propensity to participate, policies designed to meet minority needs would emphasize removing socioeconomic barriers that constrain access to recreation opportunities (Hutchison 1988; Washburne 1978). Conversely, the ethnicity hypothesis suggests that recreation resources should be allocated to reflect diverse racial and ethnic preferences (Klobus-Edwards 1981; Washburne 1978). Frome (1969; cited in Washburne 1978:176) summed up this issue thusly:

I have always considered parks, forests and wildlife refuges as manifestations of a living democracy. Now I suspect they have the same weaknesses as other institutions that need new direction. . . One sees very few Black Americans in the campgrounds, yet through their taxes they support the upkeep of facilities they cannot reach, use and enjoy for reasons ranking from the fear of hostility and discrimination to poverty.

Floyd (1991) also notes that the marginality-ethnicity framework has not been subjected to widespread empirical testing. Among the few studies that have specifically examined its hypotheses, many have found support for the preeminence of cultural preferences over socioeconomic constraints in determining at least some types of leisure behavior (Allison 1988; Dwyer and Hutchison 1990; Klobus-Edwards 1981; Stamps and Stamps 1985; Washburne 1978). For example, Dragon (1986), in one of the few studies examining recreation behavior among American Indians, concluded that underutilization of national parks by this group was related to culturally based differences in the meanings attached to parks by whites and native Americans. However, other studies report mixed results. After controlling for socioeconomic status and rural-urban residence, Washburne and Wall (1980) found that a higher percentage of whites than blacks participated in developed camping, primitive camping, boating, and sightseeing. This result supports the ethnicity hypothesis. Even so, Washburne and Wall found no significant differences in the proportion of each racial group that fished, hiked, used off-road vehicles, picnicked, or drove for pleasure-a finding that is consistent with the marginality hypothesis. Floyd et al. (1994) reported that whites and blacks who perceived themselves as middle class differed significantly from each other only in their preference for sports activities (blacks ranked them higher). There were no differences between middle-class blacks and whites in their preferences for such outdoor activities as hunting or fishing, camping or hiking, and boating or skiing. This finding also challenges the ethnicity hypothesis, although it should be pointed out that blacks and whites in this study also did not differ significantly in their preferences for outdoor recreation activities before controlling for the effects of social class. In addition, while other studies have used objective measures of socioeconomic status, such as annual household income, to evaluate the marginality and ethnicity hypotheses, Floyd et al. (1994) employed a more subjective self-report of social class. 
Dwyer's (1994) study of recreation participation in 24 different activities is one of the few investigations of the ethnicity and marginality hypotheses to compare whites, African Americans, Hispanic Americans, and Asian Americans. After controlling for income, age, gender, household size, and location of residence (which could affect opportunities to participate), Dwyer still found significant participation differences between groups across a variety of outdoor activities. In most cases, ethnic minorities had a lower rate of participation than whites, although African Americans were significantly more likely to take part in many outdoor sports, such as basketball and softball, as well as in vehicle camping. Dwyer summarized his findings by noting that, all else being equal, African Americans were significantly less likely than whites to participate in three categories of recreation behavior: (a) rural and wildland activities (hiking, observing and photographing nature, tent camping, driving for pleasure); (b) activities involving water, ice, or snow (swimming at outdoor pools, swimming at other areas, water-skiing, motorboating, sailing, canoeing, downhill skiing, ice skating, cross-country skiing); and (c) activities that are relatively expensive to participate in (golf). However, blacks and whites did not differ in their participation rates in fishing and hunting, nor did they differ in such low-cost and accessible activities as jogging, walking, and picnicking.

Asian Americans in Dwyer's analysis were less likely than whites of similar socioeconomic status to participate in only 3 of the 24 activity types: swimming at pools, bicycling, and softball and baseball. Hispanic Americans were less likely than whites to take part in only four activities: downhill skiing, water-skiing, motorboating, and bicycling. ${ }^{1}$

In some cases, ethnic differences in participation are minimized when members of all ethnic groups are subject to the same pervasive constraints on outdoor recreation participation, such as low income, advanced age, and distance from opportunities. ${ }^{2}$ For example, a study of the recreation behavior of African Americans and whites residing in an inner-city neighborhood in Pennsylvania (Cheek, Field, and Burdge 1976) reported very low participation by members of both racial groups in camping, canoeing, boating, and waterskiing, activities that would not be easily accessible or affordable by such a population. McGuire et al. (1987) found very few differences in recreation participation patterns between elderly black and elderly white respondents. Both groups reported that fishing, gardening, walking, and picnicking were favorite leisure activities. Even so, the perceived constraints to recreation

\footnotetext{
1 It should be noted that in Dwyer's analysis, as in many others, the lack of racial and ethnic differences in participation rates in some recreation activities occurs because the activities are uncommon, i.e., only a small proportion of the adult members of any ethnic group participates in them. Examples of such activities include soccer, horseback riding, jet-skiing, windsurfing, ice-fishing, and kayaking.

2 For an exception to this generalization, see Floyd et al. (1994). In this study, the greatest differences between blacks and whites in their "favorite" leisure activities occurred between respondents who rated themselves as being "poor" or "working class," and thus supposedly subject to the same broad economic constraints on their outdoor recreation participation.
} 
participation did differ: lack of money and transportation were the primary barriers identified by older blacks, while lack of time and overcrowding were the constraints identified by elderly whites.

Similarities between the recreation behavior of blacks and whites also have been reported at the opposite end of the recreation continuum, i.e., for highly accessible and inexpensive near-home activities that do not require special equipment or skill, such as walking for pleasure, jogging, and picnicking. In many studies, the proportion of African Americans and whites participating in these activities is very similar (Dwyer 1994; USDI National Park Service 1986).

\section{Gender and marginality-ethnicity}

In recent years, a research literature has emerged on gender differences in leisure behavior (Henderson 1990). Three basic tenets of this literature are (a) women occupy a generally lower status in society than men; (b) the primary obligations females face in daily life (e.g., child care) are often markedly different from those of males; and (c) as a consequence of women's social inequality vis-a-vis men, women's perceptions of what constitutes leisure, as well as their leisure schedules and activities, frequently deviate from men's. For example, women may combine their social role obligations with their leisure activities much more often than men do (Henderson et al. 1989). Thus, although both men and women may swim, men may do it as a form of recreation, while women may do it as part of child care. This implies that, in combination with ethnic background, gender may exert a strong influence on leisure patterns. The usual social context experienced by African-American women in the U.S. could lead to dramatically different views of appropriate leisure behavior than the usual social context experienced by white women or by African-American males.

Floyd et al. (1994) reported one of the few marginality-ethnicity studies that examined the joint effects of race, socioeconomic status, and gender on recreation activity. (This study investigated preferences for activities rather than participation, so its results may not be comparable with participationbased studies.) After controlling for the effects of perceived social class on leisure preferences, white males and black males who considered themselves to be members of the poor or working classes did not differ significantly in their favorite leisure activities, supporting the marginality hypothesis. In contrast, white and black women who saw themselves as being poor or working-class differed considerably, indicating that the interaction of race and gender can have major impacts on leisure. Specifically, white females ranked outdoor activities and camping second and third in their leisure preferences, while black females ranked these same activities seventh and tenth, preferring instead relatively home-centered pursuits such as resting, watching television, visiting friends, and participating in church and other voluntary organizations. The authors pointed out that, compared with males and white females, black women occupy the lowest income and occupational strata in society (Malveaux 
1988). As a result, they suffer under the joint effects of racism and sexism, which tends to constrain and differentiate their leisure, not only from that of men, but from nonblack women of similar economic position. In a comparable vein, Taylor (1992) found that African-American women living in New Haven, CT, were less likely than whites or black men to use the city park closest to their home.

\section{Summary}

The patterns described above suggest that cultural preferences may sometimes interact with socioeconomic status and gender to affect recreation behavior. When people have very limited access, resources, and opportunity, their participation rates in inaccessible and relatively expensive activities, such as wildland recreation, tend to be low, regardless of their racial or ethnic background. Similarly, when there are few constraints on access, participation rates may be high, irrespective of race or ethnicity. However, between these two extremes, participation differences between blacks and whites often exist, even when socioeconomic factors are controlled. This implies that subcultural preferences play a significant role in determining many, although by no means all, forms of outdoor recreation behavior. As a status variable, gender appears to be especially important in the case of African Americans. Limited data indicate that poor African-American women may be the least inclined to participate in outdoor recreation, preferring instead more urban, homecentered activities. Because a disproportionate share of single-parent households in the U.S. are headed by black females (U.S. Census 1990), ${ }^{1}$ this may contribute to the lower participation level of African Americans in many forms of outdoor recreation activity.

\section{Ethnic Differences in Activity Participation}

It is difficult to synthesize the many studies of ethnic and racial differences in recreation participation that have not adopted a marginality-ethnicity approach. Different sampling frames, disparate measures of recreation participation, and dissimilarity in geographic contexts often produce conflicting results. For example, national surveys are notoriously poor at taking into account regional differences in recreation opportunities that may covary with regional differences in the ethnic make-up of populations. If, nationally, blacks participate less in primitive recreation activities than whites, is it due to cultural preference or to the fact that there are more primitive recreation opportunities in western States than in the Southeast and eastern States where the greatest percentage of African Americans live? Despite these difficulties,

\footnotetext{
1 The percentages of total households with children under 18 years of age that are headed by single females are as follows: white-15.8 percent; black-50.0 percent; American Indian, Eskimo, and Aleut-8.5 percent; and Asian and Pacific Islander-11.6 percent (U.S. Census 1990).
} 
certain broad patterns in recreation participation seem evident. These are described below.

Broadly speaking, whites and Hispanics seem to be more similar in their recreation participation patterns than whites and African Americans. One of the few published national studies to compare the recreation participation rates of whites, blacks, and Hispanics was the U.S. Pleasure Travel Market Study conducted in 1989 by Longwoods Research Group Ltd. (Dwyer 1994). In this survey, whites and Hispanics were reported to be similar in their recreation-participation profiles, with both groups exhibiting higher rates of participation than African Americans in activities that usually occur in wildland settings (Dwyer 1994). (These comparisons did not control for socioeconomic differences between groups, so they cannot be viewed as tests of the marginality-ethnicity hypotheses.) A fourth ethnic category described as "Other" (presumably comprised mostly of Asian Americans) also tended to be more similar to whites and Hispanics than to African Americans. Of particular relevance to the Corps of Engineers, a smaller proportion of blacks than other groups participated in water-based recreation activities, including swimming, freshwater fishing, power boating, saltwater fishing, water-skiing, and sailing (Dwyer 1994). (Results from this and similar national and statewide recreation surveys must be qualified by pointing out that "recreation participation" is usually defined as taking part in an activity at least once during the previous 12 months. Thus, group differences in the frequency of participation are not measured.)

At least one national study has addressed the frequency issue by asking respondents which types of recreation activities they participated in "often" or "very often" (Market Opinion Research 1986). Although statistical significance levels were not reported, the percentage of Anglos and Hispanics who participated frequently in 35 different recreation activities differed by more than 10 percentage points in only three cases: running or jogging (Hispanics, 26 percent; Anglos, 15 percent), driving for pleasure (Hispanics, 54 percent; Anglos, 42 percent), and attending zoos or fairs (Hispanics, 34 percent; Anglos, 16 percent). Although other demographic characteristics were not controlled, it seems likely that these three differences in frequent participation may be due to the generally younger age of the Hispanic population in the U.S. compared with the Anglo population.

The same national survey reported that the percentage of whites and blacks who were frequent participants differed by more than 10 percent in only 4 of 35 cases. A higher proportion of blacks participated frequently in basketball ( 27 versus 8 percent), softball or baseball (27 versus 15 percent), and as spectators at outdoor concerts ( 21 versus 9 percent). Conversely, more whites were frequent participants in swimming in an ocean or lake (33 versus 21 percent). However, no substantial differences were found for frequent participation in such outdoor recreation activities as picnicking, fishing, hunting, motorboating, recreational vehicle camping, off-road vehicle use, day hiking, tent camping, canoeing, bird-watching, and sailing. In some cases (i.e., tent camping and canoeing), neither blacks nor whites were frequent participants. 
Once again, because this study did not control for differences in socioeconomic status between ethnic groups, it cannot be interpreted as a test of the marginality-ethnicity hypotheses.

A national study reported by Floyd et al. (1994) found that blacks were more likely than whites to consider exercise and "associational" recreation (e.g., attending dances, parties, church activities, and visiting friends) as their favorite forms of recreation, while whites were more apt to favor such outdoor activities as swimming, bicycling, and sailing. Even so, blacks tended to rank some forms of outdoor recreation, such as hunting and fishing, higher on their preference list than did whites.

A statewide survey of Texas residents (Adams and Thomas 1989) found that participants in "appreciative" outdoor recreation activities, such as wildlife observation, photography, wildflower study, hiking, backpacking, boating, and wildlife feeding, were predominantly white (70 percent), with lesser representation by blacks (10.3 percent) and Hispanics (18.4 percent). However, participants in "utilitarian" recreation activities, including hunting and fishing, were almost evenly split between whites (41.3 percent) and Hispanics (39.7 percent). Fewer of the utilitarian recreationists were African American (19.1 percent).

Anglo-Hispanic similarities were also reported in a regional survey of households in the Phoenix metropolitan area and an adjacent nonmetropolitan county (Gramann and Floyd 1991). This study uncovered no significant differences between Anglos and Mexican Americans in the percentage who had participated at least twice in 18 of 23 recreation activities during the previous year. Of the five statistically meaningful differences, Anglos were more likely than Mexican Americans to have taken sightseeing trips ( 75 versus 52 percent) and to have visited archeological or historic sites (59 versus 42 percent). Mexican Americans were more likely to have fished (52 versus 37 percent), camped in a tent (45 versus 35 percent), and ridden a mountain bike ( 23 versus 14 percent).

The U.S. Fish and Wildlife Service's National Survey of Fishing, Hunting and Wildlife Associated Recreation examines participation differences between whites, blacks, and "others" in outdoor recreation activities of particular interest to the Army Corps of Engineers. In 1985, fishing participation for the population 16 years old and older varied substantially by race, a finding which is somewhat at odds with other research. Among whites, 24 percent fished in freshwater areas, compared with 11 percent of blacks and 13 percent of people of all other races (U.S. Fish and Wildlife Service 1988). These figures were not substantially changed from those of 1980 (U.S. Fish and Wildlife Service and U.S. Bureau of the Census 1982). There was less discrepancy in participation rates in saltwater fishing (a less common activity). In this case, only 8 percent of whites 16 years of age and older participated, compared with 4 percent of blacks and 8 percent of those of other races. 
According to the USFWS, whites were also more likely to hunt in 1985 (10 percent) compared with blacks ( 2 percent) and to people in other racial groups ( 3 percent). As with fishing, these percentages did not change meaningfully from 1980 . However, greater racial differences were seen in participation in "primary nonresidential" wildlife-associated recreation. This was defined as taking a trip of at least $1.6 \mathrm{~km}(1 \mathrm{mile})$ for the primary purpose of observing, photographing, or feeding fish and wildlife (excluding trips to zoos, circuses, aquariums, and museums). Among whites 16 years old and older, 18 percent participated in such an outing at least once in 1985, compared with 4 percent of blacks and 7 percent of those of all other races (U.S. Fish and Wildlife Service 1988). These rates were virtually identical to those reported in 1980. One exception is that participation by "others" in primary nonresidential activities increased by more than threefold in the 5-year period, from less than 2 percent in 1980 (U.S. Fish and Wildlife Service and U.S. Bureau of the Census 1982) to 7 percent in 1985.

Some studies of participation differences have focused specifically on urban recreation facilities and services. Results tend to be inconsistent, varying by geographic location and the ethnic composition of the population. For example, although Hispanics and Anglos were found to be more likely users than blacks of public swimming pools in Austin, TX, African Americans were the more likely users in Dade County, FL (Howard and Crompton 1984). Part of this difference could be due to ethnically based differences between Mexican Americans in Texas and Cuban Americans in Florida.

Glass, Muth, and Flewelling (1990) cited several studies that showed that many rural populations in North America still rely, at least in part, on fish, wildlife, and plant resources for sustenance. Hence, subsistence harvesting may account for the relative popularity among some minority populations of fishing and hunting versus other types of outdoor activities. Taylor (1989) maintains that hunting and fishing continue to be favorite recreation activities for many black Americans because they were among the very few forms of outdoor recreation that blacks were allowed to participate in during the slavery period. Hutchison (1992) offers as one reason for the popularity of hunting and fishing among recently arrived Hmong immigrants in Wisconsin the fact that most Hmong men hunted and fished in their native Laos as a form of subsistence.

Research on participation differences between ethnic groups that does not control for socioeconomic differences has found many similarities, as well as differences, in leisure behavior. In general, fewer differences in outdoor recreation behavior have been reported between whites and Hispanics than between whites and African Americans. Asian Americans also tend to be more like whites than blacks in their recreation behavior. In the case of consumptive wildlife activities, such as hunting and fishing, similarities in participation rates may mask ethnically based differences in the meanings of these activities. Specifically, members of some groups, including ethnic minorities, still occasionally use hunting and fishing as a form of subsistence, rather than as a form of recreation. 


\section{Ethnic Differences in Travel to and Use of Outdoor Recreation Areas}

Studies of ethnic differences in the utilization of different types of outdoor recreation areas (as contrasted with participation in recreation activities) tend to mirror the results of research on participation rates. In general, black Americans are less likely than whites to visit wildland areas such as national parks. A national survey conducted in 1982 found that 83 percent of African Americans had never visited a national park, compared with 42 percent of white Americans (USDI National Park Service 1986). The national travel survey reported by Dwyer (1994) found that, among U.S. adults, blacks were significantly less likely than whites, Hispanics, or members of other ethnic groups to visit national or state parks, historic sites, or museums. A comparison of the recreation patterns of blacks and whites in eight California cities (Washburne 1978) found that whites were more than twice as likely to travel to regional or remote parks, but that visitation to local parks did not differ significantly between these two groups.

In general, African Americans tend to stay closer to home than whites when engaging in outdoor recreation (Dwyer 1994; Dwyer and Hutchison 1990; Washburne and Wall 1980). In his review of pleasure-travel research, Dwyer (1994) reported several studies that showed that whites were most likely to travel for recreation, while African Americans were least likely, with other racial and ethnic groups falling in between. A statewide study in Indiana found that blacks were more apt to use city and town resources for outdoor recreation activities than rural resources (O'Leary and Benjamin 1982). West (1988) reported that white residents in the city of Detroit were more likely to travel to parks located outside the city limits, while blacks tended to use parks within the city. In part, this was because fewer African Americans than whites owned automobiles. Scott and Munson (1994) found that blacks were more likely than whites to be nonusers or infrequent users of parks in the seven-county Greater Cleveland area. On the other hand, blacks also were more likely than whites to indicate that they would visit Greater Cleveland parks more frequently if there was more convenient public transportation. Washburne and Wall's analysis of national survey data also showed that African Americans were significantly more likely than whites to report lack of transportation as a constraint to their use of outdoor recreation areas. According to these researchers, blacks tended to use recreation areas within a 15-min walking distance of their home, while whites preferred areas within a 1-hr drive. Both groups made fewer trips to more remote zones.

The tendency for minority-group members to travel shorter distances for recreation is also seen in comparisons between Anglo Americans and Hispanic Americans. However, the trend is not as clear-cut as it is in black-white comparisons. In their Phoenix-area study, Gramann and Floyd (1991) found that Anglos were significantly more likely than Mexican Americans to have visited national parks, national monuments, and national forests outside the city at least twice during the previous year. Conversely, there were no 
statistically significant differences in the percentage of each group that had visited city and neighborhood parks.

The city of Phoenix is located close to several reservoirs on the Salt River that receive heavy recreational use. Gramann and Floyd (1991) found no differences between Anglo Americans and Mexican Americans in the number of recreational visits to Canyon Lake, Apache Lake, or Roosevelt Lake. However, Mexican Americans made significantly fewer trips to Saguaro Lake, the closest of the reservoirs to Phoenix. Gramann and Floyd noted that this was not because Mexican Americans did not use the reservoir, but because Anglo use was extremely heavy (some Anglos reported as many as 100 visits during the previous year).

\section{Perceived Discrimination and Underutilization}

The role that perceptions of discrimination might have on recreational travel by minority-group members has been investigated only recently. Gobster and Delgado (1992) reported that 1 in 10 minority-group users of Chicago's Lincoln Park stated that they had been discriminated against in the park. Reports of discrimination were highest among blacks (14 percent), and somewhat less among Hispanics (7 percent) and Asians (9 percent). Sources of reported discrimination were most often said to be other users and police. Outley (1995) reported that African Americans' use of a forest campground in southern Illinois was discouraged by a sign, apparently posted by other campers, that read "Niggers not welcome here."

West (1993) speculated that African Americans still fear the potential for discrimination and bigotry in trips through "unknown" terrain. He related the example of minority youth in New York City who would not travel to Gateway National Recreation Area, which is located within the city limits. According to West, the reason for their reluctance was fear of unknown "white" territory that lay between them and their destination. When NPS rangers offered to take the youths to the park by boat, they readily agreed. In a different context, West found that blacks were more likely than whites to indicate that "interracial" factors were a reason that they did not travel to regional parks located outside the city of Detroit. Blahna and Black (1992) conducted focus group interviews with several minority groups in Chicago and found that perceived discrimination was an important reason cited by both blacks and Hispanics for not visiting some areas. An example of reported discrimination by both visitors and police is illustrated in the following story related by an African-American focus-group participant (Blahna and Black 1992:113):

My friends and I, three years ago, were riding our bikes. When we got to the beach (which was in a White neighborhood), I said: 'This is one of the cleanest beaches I ever saw.' And so we began to ride through and everybody was staring at 
us, and when we were leaving some White boys said:

'Niggers, get out of our beach.'. . . and they threw bats and balls at us. We passed the fieldhouse director and we saw two (White) policemen and told them what had happened and they told us we shouldn't have been there in the first place. They told us to go to (a beach in a Black neighborhood).

In focus groups involving black residents of St. Louis (Wallace and Witter 1992), participants indicated that they did not camp because they felt that they would not be safe from racial intimidation. They also expressed a reluctance to go to places where African Americans did not constitute a majority of the visitors, commenting that they would visit an urban nature center in Missouri only if they were invited by staff, there was assurance that they would be made to feel welcome, and that it was safe to take their families. Taylor's (1992) study of urban park users in New Haven, CT, also found that blacks preferred to visit parks where they could see other African Americans recreating.

Taylor (1989) traced the history of discrimination in outdoor recreation areas in the U.S. during the twentieth century, describing several documented cases prior to World War II of blacks and Mexican Americans being attacked, beaten, and in some instances killed because they visited "white" beaches, playgrounds, pools, or parks. She argues that many African Americans who are alive today either personally experienced these conditions or were told of them by those who did. For this reason, Taylor believes that blacks are still reluctant to visit recreation areas where they feel that there is a chance they will not be welcome. This view was recently supported by an African American who formerly served as assistant superintendent of Yosemite National Park in California. When asked by a Los Angeles Times reporter why more blacks did not visit national parks, he replied: "It's everything from bugs to snakes to dirt to the idea that you may have to travel through rural America, where you might not be made to feel welcome" (Clifford 1995).

Discrimination at recreation sites may be perceived by Asian Americans as well as African Americans. Lee (1972) noted that Chinese residents of a California community were hesitant to visit a nearby regional park for racial reasons. As one of Lee's Chinese informants commented (1972:79):

Garfield Park is not for Chinese. They cannot feel that it is their own. After all, it is only very recently that they have been permitted to use it. It belongs to the White American culture.

Floyd, Gramann, and Saenz (1993) examined the effect of perceived discrimination on travel by Mexican Americans to several outdoor recreation sites in the Phoenix area. The authors reported a tendency for perceptions of discrimination to be associated with a reduced probability of visiting 8 of the 13 sites examined; however, none of these relationships was statistically significant. Unlike other studies, this research did not measure perceived 
discrimination at particular recreation areas, only the feeling that minorities experienced discrimination at outdoor recreation areas in general.

Chavez $(1991,1993)$ examined perceptions of discrimination among Hispanic and Anglo visitors to a wildland recreation area in southern California. Hispanics were more likely than Anglos to perceive themselves as targets of discrimination. According to Hispanics reporting discrimination, the primary perpetrators were law enforcement officers (many of whom appeared to be Hispanic), followed by other visitors.

Anecdotal evidence also supports the salience of perceived discrimination to Hispanic Americans. A Mexican-American physician in Los Angeles who is a frequent visitor to national parks in the Southwest told a Los Angeles Times reporter that she is still apprehensive about traveling to parks outside the region (Clifford 1995):

I look Indian. When I go to one of the parks in Arizona, I'll stay at a hotel on a Navajo Reservation where I know people are going to think I am one of them. But I haven't gone to any of the parks in Wyoming or Montana, and I guess that has something to do with the feeling of apprehension about going into unknown territory."

Visitors who stop using a particular recreation area because of undesirable changes in social conditions are said to be "displaced" (Schreyer and Knopf 1984). Similarly, potential visitors who never travel to an area in the first place because they expect to encounter negative circumstances onsite or en route are said to engage in "avoidance." That such processes are very real and may affect millions of residents around a recreation area has been demonstrated by recent research (Gramann 1991). However, the concepts of displacement and avoidance have rarely been linked to ethnic issues in recreation behavior.

Ethnicity and/or race may be associated with displacement and avoidance in at least two ways. First, minority groups may avoid certain areas where they expect to experience discrimination, either from other visitors or from managers. Second, a recreation locale may develop a specific identity as a site affording particular types of experiences that are desired by a cultural group (Williams and Carr 1993). For example, Lee (1972) described parks that were thought by their users to "belong to" a particular race, age, or sex grouping. Although members of the "possessing group" were comfortable in such areas, members of other groups avoided them. An example of how the identity of a locale can shift over time is seen in the use of several outdoor recreation areas near Los Angeles that were formerly dominated by Anglo users, but are now dominated by Hispanic users (Chavez, Baas, and Winter 1993; Chavez and Winter 1993). Such shifts in the social definition of a recreation place may be a catalyst for ethnically related displacement and avoidance. In this regard, it is useful to recall the earlier comments of 
African Americans who said they preferred to visit recreation places where they would see many other members of their racial group.

\section{Projections of Future Activity Participation}

A few attempts have been made to project future participation in specific outdoor recreation activities based on the expected size and composition of the U.S. population. These so-called "cohort-component projection models" (Dwyer 1994) are generally based on likely changes in the number of persons in various race, ethnicity, and age groupings. Such projections generally assume that there will be a constant relationship over time between people's age and ethnicity and their propensity to participate in different types of recreation activities (Dwyer 1994; Murdock et al. 1991; Murdock et al. 1990). In other words, it is assumed that the proportion of a particular population group (e.g., young African Americans) who take part in an activity will not change, even though the number of U.S. residents belonging to that population cohort may increase or decrease over time.

Projections of activity participation into the next century generally conclude that age will be the primary influence on demand for different outdoor recreation activities, but that ethnicity will also have a significant impact. For example, participation in backpacking is expected to drop significantly by the year 2025 , primarily because this is a recreational pursuit associated with young whites, and the number of whites 20 to 24 years of age is expected to decline by 2025 (Murdock et al. 1991). In contrast, overall participation rates in bird-watching, hunting, day hiking, tent camping, walking for pleasure, and picnicking are all anticipated to increase, largely because more of the minority population in the U.S. will be in age brackets in which participation in these activities is most likely to occur (Dwyer 1994). Ethnicity is expected to be particularly important in driving the increase in demand for hunting and day hiking (Murdock et al. 1991), although it will still be less important than age in bringing about this change.

Dwyer (1994) cautions that national projections of recreation demand, such as those by Murdock et al. (1991), obscure significant variations in future participation that are likely to occur at regional or State levels. Such diversity will almost certainly take place because the geographical distribution of minority groups across the U.S. is uneven. A second weakness of national projections is that, because of limitations in available data, they often are unable to take into account other factors, in addition to age and ethnicity, that may affect outdoor recreation demand. Finally, it is not at all clear that the basic assumption of cohort-component projections, i.e., that there will be constant activity-specific participation rates by different demographic cohorts over time, is correct. Based on the early theoretical work of Thorstein Veblen (1899), West $(1985,1984,1982)$ hypothesized that certain types of recreation activities, such as sailing, are relatively "high-status" activities in that they are initially participated in by persons belonging to upper socioeconomic classes. According to West, through a process of "status-based diffusion," 
participation in these activities may spread to progressively lower status groups who adopt the activities as a way to emulate persons of higher social standing, thus enhancing their own status. Using two national surveys conducted 5 years apart (1972 and 1977), West (1982) demonstrated status-based diffusion effects for sailing, golf, and tennis.

Although West did not include ethnicity in his projection methodology, more recent work by Christensen (1992) utilized ethnic-group participation rates to examine trends during the 1980s in participation in six recreation activities (camping, saltwater fishing, ice skating, jogging, roller skating, and horseback riding). Christensen concluded that cohort-specific rates of participation changed considerably during the decade, casting further doubt on projection methods that assume otherwise.

\section{Summary}

Generally speaking, a higher percentage of white Americans tend to participate in wildland recreation activities than do African Americans. One frequent exception to this pattern is fishing and hunting. In some studies, blacks and whites have been found to participate at equal rates with whites in both of these activities, while in other research minority groups have participated at higher rates. One explanation for this pattern is that fishing is an outdoor activity that may be done for sustenance by some low-income minority groups. Another explanation for the popularity of fishing and hunting to blacks is that African Americans have a long tradition of participating in these activities that dates back to the slavery period. A similar tradition of participation does not exist for many other contemporary outdoor recreation activities.

In terms of both recreation participation and recreational travel, Hispanic Americans and Asian Americans tend to be more similar to Anglos than they are to blacks. However, very little data are available on the recreation participation and utilization patterns of Asian Americans. Some differences that exist between Hispanics and Anglos appear to be due to the younger age of the Hispanic population. When age is controlled in participation-rate comparisons, many of the differences between Anglos and Hispanics become insignificant (Dwyer 1994).

Research on the causes of participation-rate differences between whites and members of other ethnic groups provides mixed support for the ethnicity and marginality explanations. Various ethnic and racial minorities in the U.S. appear to have evolved different culturally based preferences for at least some types of outdoor recreation activities. However, there also exists a set of highly accessible leisure pursuits that are popular among all segments of the U.S. population, regardless of ethnic or racial background. 
One recently investigated explanation for ethnic differences in the utilization of parks and other recreation areas is perceived discrimination, either from staff, other users, or law enforcement officers. The few studies that exist suggest that perceptions by blacks and other minority groups that they are "unwelcome" by whites may reduce their travel to some areas. However, much of the evidence for a discrimination effect is anecdotal. More research is needed on this topic.

The effect of ethnicity on recreation participation has also been examined in projections of future demand for outdoor activities. These studies indicate that, taken together, ethnicity and age play an important role in shaping future demand, but that caution is needed in assuming that participation rates characteristic of a specific age or ethnic cohort at one point in time will not change. In particular, participation in some recreation activities may diffuse from one social class or cohort to another, resulting in overall growth in participation in these activities by a more ethnically and age-diverse user population. 


\section{Research on Ethnic Differences in Recreation Style}

The large representation of Hispanic groups in the visitor populations at many recreation sites in the Southwest has resulted in a downplaying of underutilization as an issue for Hispanic Americans. In its place has emerged a concern over differences in the style of Hispanic-American and Anglo use of recreation resources. As defined earlier, style is that unique quality of recreation behavior that arises from variations in group size, participation motives, spoken language, and attitudes towards natural resources, including facility-development preferences.

\section{Size and Composition of Social Groups}

One of the most commonly noted distinctions between Anglos and Hispanics relates to the size and composition of recreation groups. Sociologists have long recognized the importance of group characteristics in shaping recreation participation (Field and O'Leary 1973). However, recent research indicates that associations between group type and activity participation that are typical of Anglo Americans may not apply to Hispanic Americans.

Although Hispanics and Anglos often visit the same types of areas, Hispanics tend to recreate in larger social groups. In a study of Chicago park users, Hutchison (1987) reported that the average size of Anglo parties was 2.5 persons, while that of Mexican Americans was 5.7. Among campers at a national forest in New Mexico, the average number of people in Anglo groups was 6.9, compared with the Mexican-American average of 12.8 (Irwin, Gartner, and Phelps 1990). In Yosemite National Park, the mean party size was 3.1 for Anglos, while the average for Hispanic visitors was 4.4 (Gramann 1991).

Larger groups among Hispanics often are the result of differences in party composition. Carr and Williams (1993) reported that, among visitors to two national forests near Los Angeles, Hispanics were more likely than Anglos to 
be visiting as part of an extended family (50.6 percent versus 30.0 percent). Hutchison (1987) found that Mexican Americans using Chicago parks typically visited as part of nuclear or extended families. In contrast, Anglos and blacks tended to participate as individuals or as members of single-generation peer groups. The study by Irwin, Gartner, and Phelps (1990) of New Mexico campers reported that 48 percent of Anglo parties had no children present, while among Mexican Americans this figure was only 8 percent.

Many resource managers are reluctant to deal with large social groups. In fact, it is not unusual for recreation areas to regulate group size, either by restricting the size of parties that can enter an area without permission, or by limiting the number of people, groups, or vehicles that are allowed to occupy a single campsite. In their study of campers in New Mexico, Irwin, Gartner, and Phelps (1990) reported that Mexican-American groups exceeded designated campsite capacity by an average of almost 30 percent.

\section{Participation Motives}

A strong emphasis on the extended family is a recognized hallmark of Hispanic culture (Sabogal et al. 1987). Although close family ties are hardly unimportant to Anglos, Keefe (1984) notes that the two cultures differ on what is meant by "close." With regard to the extended family, Anglos are satisfied with intermittent meetings, supplemented by telephone calls and letters. In contrast, Mexican Americans place greater value on frequent face-to-face contact. While this is important to nuclear family life among Anglos, it is less integral to the extended family.

Gramann and Floyd (1991) found that "doing something with your family" and "doing something your children wanted to do" were significantly more important recreation participation motives to Mexican Americans living in the greater Phoenix area than to Anglo Americans. In their study of visitors to San Gabriel Canyon near Los Angeles, Simcox and Pfister (1990) also found that Hispanic groups placed a greater emphasis on family-related motives. In particular, Anglos were significantly less likely to rate "watching children play" as an appealing part of their recreation experience. Shaull (1993) reported that Hispanic Americans living in central and southern California rated "doing something with your family" and "bringing the family together more" as significantly more important to their outdoor recreation enjoyment than did Anglo Americans. A survey of visitors to the Mecca Hills recreation area in southern California reported that having a "place to recreate with the family" was rated as a more important site attribute by Hispanic visitors than by Anglo visitors (Baas, Ewert, and Chavey 1993).

Gramann, Floyd, and Saenz (1993) speculate that the pattern of greater importance attached to family-related recreation motives by Hispanic Americans reflects a fundamental sociological function of recreation (and leisure in general) as a means of preserving core cultural values in an Anglo-dominated society. According to these researchers (1993:71): 
. . leisure is often subject to fewer perceived pressures to conform to the expectations of others than is behavior in the workplace or at school. Hence, even though minority group members may adopt those traits of a host culture that have strategic value for advancing their own socioeconomic status, recreation may remain an important social space in which basic cultural values can be maintained and expressed.

\section{Language}

A basic concern of resource managers who deal with Hispanic visitors relates to language. The various Hispanic populations in the U.S. differ from many other ethnic groups in that they have maintained many aspects of their cultural heritage through maintenance of the Spanish language (Caraballo 1993). A common pattern among other ethnic groups is a decrease in the use of ancestral languages over time, such that in the third and subsequent generations, English becomes the first language (McLemore 1991). The persistence of Spanish among Hispanic populations is related to several factors, not the least of which is the continuing influx of Mexican, Central American, and Caribbean immigrants. In addition, many Hispanic Americans tend to settle and remain in geographically concentrated areas, where there is no great need to learn English for day-to-day living.

Many Hispanic Americans are bilingual. For this reason it is common for postimmigrant generations of Hispanics to speak both English and Spanish fluently (Keefe and Padilla 1987), often switching from one language to the other in midsentence. Take, for example, the following patter by a disk jockey on a Spanish-language radio station in Texas (Caraballo 1993:85):

Buenas tardes, and T.G.I.V. (Thank God it's viernes). Son las dos de la tarde y coming up is the tejano Madonna, Selena Quintanilla con su new hit "No debe jugar." Estamos escuchando K.B.M.A. Radio La Fabulosa, número uno en español en el condado de Brazos.

The survey of mostly Hispanic visitors to the BLM's Mecca Hills recreation area found that 36 percent spoke Spanish only, while an almost equal proportion, 32 percent, spoke both Spanish and English (Chavez, Baas, and Winter 1993). Hispanic visitors to a picnic area in the San Bernardino National Forest near Los Angeles exhibited similar language patterns: 37 percent preferred to speak Spanish most of the time, while 30 percent spoke both English and Spanish (Chavez and Winter 1993). Of 273 Hispanic users interviewed in San Gabriel Canyon near Los Angeles (Simcox and Pfister 1990), only 9 percent indicated that they used the English language most of the time, while 51 percent said they used Spanish and 40 percent often used both languages. Gramann and Floyd's (1991) telephone survey of Phoenix-area households found that 48 percent of adult Mexican-American respondents preferred to use both Spanish and English, 37 percent preferred mostly English, and 15 percent preferred mostly Spanish. Shaull's (1993) telephone 
survey of Hispanic households in central and southern California reported higher rates of Spanish-language use than in Phoenix: 27 percent of adult Hispanic respondents relied primarily on Spanish, 42 percent frequently used both languages, and 31 percent relied mostly on English. Thus, although there is a marked tendency toward bilingualism among the Hispanic-American population, exclusive reliance on Spanish varies from place to place within the Southwest, perhaps as a function of the size of the Hispanic population and the need to use English in day-to-day interactions.

Even though many Hispanic Americans speak Spanish fluently, it cannot be assumed that they read and write Spanish with equal facility (Keefe and Padilla 1987). Hispanic Americans who are educated in U.S. schools often learn to speak Spanish as a young child at home, yet do not receive instruction on how to read or write Spanish in school. For this reason, there is no guarantee that written communication in Spanish will be any more effective at reaching Hispanic visitors with a message than will written communication in English. Simcox and Pfister (1990) recommended that informational services in areas visited by Hispanic users should rely heavily on international symbols. Some resource management agencies (e.g., BLM) have emphasized Spanish-language training for law enforcement personnel and the development of public service announcements in Spanish for broadcast on local Spanishlanguage radio stations (Chavez, Baas, and Winter 1993).

\section{Attitudes Toward Natural Resources and Facility Development}

\section{Anglo-Hispanic comparisons}

The crux of concern by natural resource managers over ethnic differences in recreational style seems to revolve around presumed differences in attitudes toward natural resources. Many resource managers observe that Hispanic users seem to be motivated primarily by "social" experiences and are less interested in the natural resources of an area (Gramann, Floyd, and Ewert 1992). The study of ethnic variation in these attitudes is one area of recreation-style research that has included African Americans, as well as Anglo Americans and Hispanics.

Lynch's (1993) review of environmentally oriented essays and fiction by Latino writers concluded that Hispanic-American environmental perspectives differ from those of the Anglo-American mainstream in that Hispanic culture does not sever people from the natural landscape. According to Lynch, the ideal landscape depicted in Latino writings is "peopled and productive," in

contrast to the Anglo idealization of natural landscapes that are unaffected by human activities. Indeed, the Spanish language has no word that captures the full meaning of the English term "wilderness" (Pizzini, Latoni, and Rodríguez 1993). Thus, a comparison of Anglo-American and Hispanic-American environmental values as reflected in contemporary literature suggests that 
differences between the two ethnic groups may be considerable. However, social science research addressing this issue is in its infancy.

In part, the world view attributed to U.S. Hispanics by Lynch seems to result from historical differences in the development of Anglo and Hispanic culture in North America. Knowlton (1972) points out that early Hispanic settlers in the New World identified very closely with the land as a means of sustenance. Although very extensive private landholdings existed in the Spanish colonies and in postcolonial Mexico, communally owned lands, i.e., ejidos, were regarded as especially important among mestizo and native Indian populations, both for human life and village welfare. The English concepts of private property rights and human domination over nature were not necessarily antithetical to Hispanic culture, but the idea that one could monopolize vast acreages while others went landless was morally repugnant. Indeed, much of the impetus for social revolution in nineteenth-century Mexico was the restoration of communal village lands that had been absorbed into haciendas and other large private landholdings (Parks 1988). Legal battles to achieve this aim still occur in the U.S. in such states as New Mexico (Eastman 1991). This historical stake in the communal land base appears to be reflected in the environmental views of many U.S. Hispanics today.

Noe and Snow (1989/90) compared the environmental values of Hispanics and non-Hispanics in south Florida. An analysis of responses to a set of scale items known as the "New Environmental Paradigm" (Dunlap and Van Liere 1978) showed that Hispanics and non-Hispanics were similar in their agreement that humans must live in harmony with nature, that the balance of nature is easily upset, and that people are severely abusing the environment. However, non-Hispanics were significantly more likely than Hispanics to believe that humans should dominate and exploit the environment. This was reflected in non-Hispanics' agreement with such statements as "Plants and animals exist primarily to be used by humans," and "Mankind was created to rule over the rest of nature." Hispanics strongly disagreed with these positions. A study by Gramann and Saenz (1995) of the environmental values and attitudes of Anglos and Hispanics living in the Rio Grande Valley of Texas found similar patterns. Hispanics were significantly more likely than Anglos to agree that people are severely abusing the environment, that the balance of nature is easily upset, and that plants and animals have the same right to exist as humans. However, reflecting the aforementioned Latino ideal of a "peopled and productive" landscape, Hispanics also were more likely to believe that nature can cope with modern industrialization, that people have the right to modify nature, and that humankind will eventually learn enough about how nature works to be able to control it. Thus, although Hispanic Americans seem to perceive the natural environment as more fragile than do Anglos, it appears that this attitude does not preclude the possibility of enlightened human dominion over nature.

Differences between ethnic groups in attitudes toward natural resources can be reflected in the importance of nature-related motives for recreation participation. When asked their views about "respecting the forest," Anglo visitors 
to the Angeles and San Bernardino national forests in southern California were more likely to give interpretations related to their own behavior, such as not littering and cleaning up after themselves (Carr and Williams 1993). In contrast, Hispanic visitors were more likely to interpret respecting the forest in a more reciprocal fashion to mean ensuring clean air and water for themselves, maintaining a safe place to visit, and treating the forest as one would treat oneself. Mexican-born Hispanics and Central American-born Hispanics visiting the San Gabriel Canyon near Los Angeles rated "learning about nature" as a more important participation motive than did Anglos (Simcox and Pfister 1990), although Anglos did not differ from Hispanics in the importance of two other nature-related motives-viewing scenery and viewing wildlife. Interestingly, Hispanic groups also rated "talking to and meeting new people" and "doing some eating and drinking" as more important reasons for their recreation than did Anglos. Regarding the importance of both social and naturerelated motives to Hispanic Americans, Simcox (1991) observes that Hispanic groups tend to place great importance on both tranquility-seeking and socializing with others in wildland recreation areas.

Pizzini, Latoni, and Rodríguez (1993) interviewed local visitors to "El Yunque," the popular Spanish name for the Caribbean National Forest in Puerto Rico. Native Puerto Ricans expressed pride in the uniqueness of this last large tract of subtropical rainforest on their island. In contrast to international tourists, who emphasized the visual and scenic aspects of their visit, Puerto Ricans reflected on the utilitarian and spiritual values of interacting with nature. These included being able to breathe clean and cool air, appreciating the importance of nature conservation, and experiencing peace and tranquility in the presence of the work of God.

In their survey of Phoenix-area households, Gramann and Floyd (1991) reported that Mexican Americans rated "getting back to nature" as a more important reason for outdoor recreation participation than did Anglos. Consistent with the Puerto Rican study, Anglo Americans considered "being in a scenic area" to be more important than did Mexican Americans. MexicanAmerican respondents also rated "meeting new people" as an important motive, but not as important as either of the nature-related motives.

Attitudes toward natural resources also may be reflected in preferences for facilities and services at recreation sites. In particular, Hispanic Americans appear to prefer greater levels of development than do Anglos, perhaps reflecting the cultural juxtaposition of concern about environmental protection with the idealized "peopled and productive" landscape. Baas, Ewert, and Chavez (1993) reported that Hispanic visitors to Mecca Hills evaluated many types of recreation facilities as being more important than did Anglos, including parking spaces, signs, picnic areas, trails, garbage-disposal facilities, and toilets. Hispanic users of San Gabriel Canyon felt that too few parking areas, inadequate toilets, inadequate information services, and insufficient law enforcement were greater problems than did Anglo visitors. However, Anglos were more concerned about graffiti, vandalism, and water pollution in a stream that ran through the canyon. Snow (1989) found that Hispanic visitors 
to Florida's Biscayne National Park were more likely than non-Hispanics to believe that the park did not provide enough information services dealing with the area's natural environment, history, or rules and regulations. Chavez and Winter (1993) reported that over one-half of the largely Hispanic visitor population at the Applewhite picnic area in the San Bernardino National Forest wanted more parking spaces, as well as a playground added to the area. Mexican-American campers at the Sleepygrass Campground in New Mexico's Lincoln National Forest also differed considerably from Anglo campers in preferred site characteristics (Irwin, Gartner, and Phelps 1990). Anglos were more likely to list quiet surroundings, privacy, water, and space between campsites as preferred campsite characteristics, while Mexican Americans placed more importance on toilets, camping space at each site, water, and fire rings. In addition, 67 percent of Anglo campers preferred to be far away from other campers, compared with only 28 percent of Mexican Americans. Interestingly, both ethnic groups said that they preferred to camp in minimally developed campgrounds, suggesting that definitions of development levels may differ between Anglo Americans and Mexican Americans.

\section{White-Black comparisons}

Many studies have shown that African Americans and whites differ substantially in their perceptions of natural environments and in their interests in natural resource management and environmental issues (Kaplan and Talbot 1988; Kellert 1984; Taylor 1989; Wallace and Witter 1992). In general, blacks have shown less concern for certain types of environmental-protection issues and less preference for purely natural settings and nature-oriented recreation activities. Taylor (1989) offers several explanations for this trend.

One possible cause for black-white differences is that, because most African Americans have limited economic means, they cannot afford to be concerned about protecting the natural environment. Instead, they must place a higher priority on securing other basic social needs. This is similar to the marginality explanation of ethnic differences in outdoor recreation participation. It is also consistent with the popular "hierarchy of needs" theory described by Maslow (1975) that assumes that luxury items (such as environmental concern) cannot be attended to until more basic physiological and psychological needs have been satisfied.

Several writers have cited the alienating effects of slavery as an explanation for contemporary African-American attitudes toward natural resources and the land (Dolin 1988; Meeker 1992; Taylor 1989). All such arguments make reference to a speech by Eldridge Cleaver at the height of the U.S. Black Power Movement in the late 1960s. Cleaver maintained that American land was viewed by blacks as a symbol of enslavement, and that, for this reason, African-American upward mobility was measured in degrees of removal from the soil. Taylor points out that Cleaver's remarks are actually taken out of context, and that in the same essay that supposedly affirms black alienation from the land, Cleaver makes references to "a deep land hunger in the heart 
of Afro-America" (Taylor 1989:186). Nevertheless, others still argue for a symbolic aversion to the land as being an important inhibitor of AfricanAmerican use of some types of outdoor recreation areas. In an interview with the Los Angeles Times, the president of the association of black travel agents commented (Clifford 1995):

I don't think people two generations away from sharecropping are interested in going back to the fields on their vacations. When people who have been poor a long time suddenly can afford a vacation, they're going to want to spend it on something a little more luxurious than a campground in the middle of nowhere.

Taylor contends that one plausible explanation for blacks' greater indifference to natural environments is rooted in the content of African-American mythology, which often depicts forests and woodlands as being inhabited by ferocious or highly exaggerated forms of wildlife, such as elephants as big as houses and snakes that can crush a man or horse. Taylor speculates that such tales can leave lasting impressions on young audiences, resulting in an enduring fear of wildlands and a lack of desire to enter them. This argument is supported by comments made by black adults in focus group interviews conducted in St. Louis by the Missouri Department of Conservation (Wallace and Witter 1992). Participants reported that fear of wildlife was one reason for their lack of interest in outdoor recreation environments. Many were afraid they would encounter snakes, bears, foxes, and skunks in natural settings, all of which were viewed as undesirable and potentially dangerous species. Several commented that they would go to outdoor settings only if they were sure that nature, as well as humans, could be controlled.

African Americans' preference for highly managed natural settings has also been documented in several studies involving preference ratings of color photographs taken of urban versus rural scenes. In their review of this research, Kaplan and Kaplan (1989) argued that nature is not necessarily unimportant to urban blacks (as is sometimes concluded), but that human influence, neatness, and openness are far more preferred in natural settings by blacks than by whites. For example, in a study of the environmental preferences of Chicago school children visiting an urban nature center, Gobster (1992) showed that African-American children tended to prefer more open settings, and that densely forested areas were associated with fear and danger. Kaplan and Kaplan (1989) cited a study by Medina (1983) that found that a sample of predominantly black school children in Detroit were less likely than environmental educators to prefer urban scenes marked by tree-lined streets, parks, and fields. Instead, the school children rated scenes with row housing, single-family residences, and commercial areas as more preferred. Anderson (1978) sampled black and white high school students and residents of a rural area where forestry was a major industry. Whites were more likely to prefer scenes showing dense forests, while blacks showed a stronger preference for "planned spaciousness," i.e., relatively open scenes suggesting human influence, including the presence of roads and picnic tables. (Whites also preferred these scenes, but not as strongly as blacks.) Anderson recounted 
additional anecdotal evidence supporting his findings concerning black aversion to some types of forest settings. As quoted in Kaplan and Kaplan (1989:99-100), while taking photographs for his study:

.. he consulted some local individuals about where he might find some particularly attractive scenes. At least one black resident explained to him that "there weren't any anymore; the trees are all grown up now." . . .when asked for some advice about getting back into town a black merchant provided some lengthy instructions. When asked whether it would not be shorter to take a different route he replied: "You don't want to go through the forest, do you?"

Kaplan and Talbot (1988) compared the environmental preferences of white residents of Ann Arbor, MI, with those of black residents in Detroit. Whites more strongly preferred scenes characterized by an undeveloped or unmanicured appearance, while blacks gave higher preference ratings to scenes that included built elements, such as benches, park equipment, paved walks, and picnic shelters. In addition, African Americans expressed dislike for scenes that were "too enclosed" or "too confined." Kaplan and Talbot stress that these results do not mean that blacks simply prefer built over natural settings. Rather, they reflect preferences for different arrangements within an outdoor setting. In fact, when asked about their actual contacts with nature, 77 percent of the black residents said that they considered nature to be extremely important to them, and that their involvement with nature was a very frequent concern, if not a central part of their daily lives (Kaplan and Talbot 1988:115).

Findings from studies of facility preferences among black visitors to outdoor recreation areas are consistent with results from visual-preference research. Washburne and Wall (1980) reported that black residents of eight California cities were more likely to support Federal spending on building more recreation facilities, while whites supported acquisition of more land. Dwyer and Hutchison's survey of Chicago residents found that a higher percentage of African Americans than whites preferred developed facilities and conveniences in recreation areas ( 53 percent versus 24 percent), while whites were more likely to prefer preserved natural areas (57 percent versus 27 percent). African-American and white visitors to metropolitan parks in the Greater Cleveland area also differed in their preferences for development levels. Twenty-two percent of African-American visitors favored more development, compared with only 13 percent of white visitors (Scott 1993).

Concern over personal safety appears to affect the facility and service preferences of some African Americans. Black focus-group participants in St. Louis mentioned security and protection from random violence as important features of desirable urban nature centers (Wallace and Witter 1992). They preferred areas that were well-lighted, where authorities kept track of who went in and out, and where they could take their families "without all these teenagers around acting crazy" (Wallace and Witter 1992:23). In a similar vein, black residents of northeast Ohio were more likely to cite fear of 
crime as a reason for not visiting certain urban parks than were whites (Scott 1993), as were African Americans in New Haven, CT (Taylor 1992).

\section{Summary}

Research on ethnic differences in recreation style has emphasized distinctions between Anglos and Hispanics. In general, Hispanic Americans are more likely than Anglos to participate in outdoor recreation activities as members of large social groups, including extended families.

Many Hispanic Americans are bilingual, while others speak primarily Spanish. However, for most Hispanics, the ability to read and write in Spanish is not as well-developed as their skills in speaking Spanish. This indicates that Spanish-language communication with Hispanic visitors will be more effective if it is in the form of oral communication rather than written communication.

The Hispanic relationship to the natural world seems to be one that incorporates human beings as an integral part of the landscape, rather than as a species set aside from nature. This orientation may account for Hispanic Americans' greater preference for developed facilities and services in outdoor recreation areas as compared with Anglos. The pattern of ethnic-group differences extends to black-white comparisons as well. African Americans prefer more managed and developed outdoor recreation settings than do whites. African Americans are also more likely to list safety concerns as a factor affecting their park use. 


\section{Research on Acculturation and Recreation}

Assimilation has been defined as "a process of boundary reduction that can occur when members of two or more societies or of smaller cultural groups meet" (Yinger 1981:249). In North America, sociological research on cultural assimilation (or acculturation) has been guided by three competing ideologies: Anglo-conformity, the melting-pot model, and cultural pluralism (Gordon 1964).

The Anglo-conformity ideology "assumes that an ethnic minority should give up its distinctive cultural characteristics and adopt those of the dominant group" (Yetman 1985:220). In contrast, the melting-pot model views assimilation as a process in which ethnic differences are shed in the creation of a new people "unique and distinct from any of the groups that formed it" (Yetman 1985:221). Finally, cultural pluralism views assimilation as an accommodation of ethnic-group differences within a single political system.

Gordon (1978) asserts that the Anglo-conformity model best describes the assimilation experiences of immigrants to the United States. He contends that those groups that have been able to adapt to the values, culture, and institutions of the Anglo-American majority have had less difficulty being accepted into society's mainstream. In contrast, more culturally and racially distinct groups have experienced greater problems.

The Anglo-conformity model seems inappropriate for understanding ethnic influences in outdoor recreation. As noted previously, there are many differences between whites and other ethnic groups in recreation behavior and style that appear to be influenced by cultural values that are different from those of whites. In this vein, sociologists who study leisure behavior (e.g., Kelly 1987) frequently describe leisure as individually and culturally expressive. Even though immigrant groups may quickly adopt those traits of another culture that have special worth for advancing socioeconomically, over time, leisure can remain an important arena in which ethnic values are maintained and expressed.

Another reason that the Anglo-conformity model might be inappropriate as an explanation for recreation behavior is that when ethnic groups view 
themselves as persecuted or discriminated against, they often react by maintaining social, psychological, and physical boundaries between themselves and other groups (Buck 1978). These boundaries inhibit the assimilation process. Buck (1978:227-228), quoting Loomis and Beegle (1957), defines this process of "boundary maintenance" as:

. . .activity to retain identity, value orientation, and (the) interaction pattern of a social system. The process of boundary maintenance actively resists forces which tend to destroy the identity and interaction pattern.

Boundary maintenance may be one reason for the persistence, despite increasing contact with other cultures, of the distinctive ethnic identities of Old Order Amish in Pennsylvania (Buck 1978), Native Americans in the Southwest (Allison 1993), and recent Hmong immigrants who have settled in California and the Great Lakes region (Hutchison 1992). These and other cases strongly imply that interaction between minority and majority groups does not always lead to full acculturation, as predicted by the Angloconformity model. On the contrary, interaction may actually produce active efforts to protect core cultural values from assimilation pressures. For example, Hutchison (1992) points out that among Southeast-Asian Hmongs who have settled in several Wisconsin cities, there is a strong commitment to preserving traditional family clan structures and other cultural traditions, even among the first generation now growing up in the United States.

\section{Selective Acculturation}

An alternative to the model of strict Anglo-conformity is found in a variation of the cultural-pluralism model known as "selective acculturation" (Keefe and Padilla 1987). Selective acculturation appears to be particularly descriptive of the assimilation experience of several U.S. immigrant groups, including the Hmong and many Hispanic-American populations. Several authors have observed that, as a group, Mexican Americans have felt pressure to conform to Anglo-American values, but also have resisted total assimilation by maintaining cultural ties to their Mexican heritage (McLemore 1991; Teske and Nelson 1976). Because of its expressive nature, leisure may play an important role in the process of selective acculturation. According to Kelly (1983:32-33):

Culture. . .is one dimension in the content of leisure. What is consumed, played, encountered and observed in leisure events is of the culture. . . Further, what is defined as a viable opportunity for leisure is culturally shaped. Activities and resources that are central to the perceived opportunity contexts of one group may not even be defined as leisure by another.

In recent years, a small body of research has emerged examining the process of acculturation and its relationship to recreation behavior and recreation 
style in outdoor environments. This research has focused on various Hispanic-American groups and has been based on the proposition that ethnic minorities cannot be treated as culturally undifferentiated blocs. Rather, their recreation behaviors and styles may vary as a function of their degree of assimilation into Anglo culture. A hypothesis of particular interest is that members of ethnic minorities will become more "Anglo-like" in their recreation with increasing degrees of cultural assimilation. Assimilation in these studies is usually measured as number of generations of family history in the U.S. (generational tenure) or as use and preference for Spanish versus English in everyday settings (language acculturation). Although equally applicable to Asian Americans, very little research on recreation and Asian-American cultural assimilation has been conducted.

Keefe and Padilla (1987), in their study of assimilation among Mexican Americans in three southern California communities, asked respondents to identify the ethnicity of people they saw in places where they went for fun and relaxation (parties, dances, picnics, and so forth). Eighty-six percent of Mexican Americans who had been born in Mexico replied that they frequented leisure places where they found mainly other Mexicans, compared with 60 percent of U.S.-born Mexican Americans. Fifty-six percent of the children of U.S.-born Mexicans reported that they went to leisure settings where most of the other people were also Mexican Americans. This pattern suggests that the major effect of cultural assimilation on choice of leisure locales occurs between the immigrant generation and the first U.S.-born generation.

A study of Chinese Americans in Chicago found that older adults of the immigrant generation differed substantially from younger, U.S.-born Chinese in their leisure preferences (USDA Forest Service North Central Forest Experiment Station 1994). Older adults listed walking, socializing, and traditional exercise, such as tai-ji, as typical activities they preferred. In contrast, younger adults and children preferred activities that closely paralleled those of Euro-Americans. ${ }^{1}$

Carr and Williams (1993) reported a relationship between the generational tenure of Mexican Americans and both social group composition and interpretations of "showing respect for the forest." Although Mexican Americans were more likely than Anglos to visit a forest recreation site with their immediate or extended families, significant variation existed within the MexicanAmerican user group. In particular, the proportion who were visiting with friends increased directly with longer generational tenure in the U.S., so that by the second U.S.-born generation, the Mexican-American incidence of visiting with friends was more similar to that of Anglos than to less-assimilated Mexicans. U.S.-born Mexicans also were more similar to Anglos in their interpretation of the meaning of respecting the forest than were immigrants. The majority of U.S.-born Mexican Americans interpreted this phrase to refer

\footnotetext{
1 It was not clear how the researchers accounted for the independent effect of age differences on leisure preferences in this study.
} 
to specific individual behaviors, such as not littering, that were protective of the natural environment. This was similar to the proportion of Anglos who interpreted the phrase in the same manner. However, immigrants were much more likely to explain the phrase more abstractly, using meanings related to enjoying clean air and water, preserving nature; and linking respect for the forest to respect for oneself and one's home.

Gramann, Floyd, and Saenz (1993) and Shaull (1993) examined the effect of Hispanic-American acculturation on the importance of family-related and nature-related experiences in outdoor recreation. Acculturation in these studies was measured by use and preference for Spanish versus English in everyday situations. Both studies employed cluster analysis to derive three groups of Hispanics who varied by their degree of language acculturation. These were least-acculturated, bilingual, and most-acculturated. After controlling for age, education, and the number of children in a household, Gramann et al. found that family experiences were most important to the most highly acculturated Mexican Americans. Further, this importance was significantly greater than that among Anglo Americans. Interestingly, the highly acculturated group also placed more emphasis on family experiences than did the least acculturated Mexican Americans, who were not different from Anglos in this regard. This is opposite to the pattern that would be predicted by an Angloconformity model of assimilation. The researchers explained this paradox in terms of selective acculturation and the disrupting effect of immigration on local family ties. The least acculturated Mexican-origin respondents were primarily immigrants and would not be expected to have extensive local family networks. Thus, family experiences in outdoor recreation would be less important to this group. However, over generations, family networks could be rebuilt in the U.S. so that the core Hispanic value of familism could be reexpressed in the recreation styles of subsequent generations. This would explain the greater importance of familism to the most acculturated Mexican Americans. Thus, outdoor recreation appeared to provide an opportunity for certain central values of Hispanic culture to be maintained, despite assimilation on other cultural dimensions, such as language.

Shaull's central and southern California study partially replicated Gramann et al.'s findings. However, in this case, the bilingual Hispanic Americans placed the greatest emphasis on family-related experiences, while the least acculturated and most acculturated Hispanics were similar to Anglos. Shaull argued that Anglo-conformity effects could be resisted up to a point, but eventually they would impact even core values, such as familism. This conclusion was consistent with the findings of a study of recreation visitors to a national forest outside of Los Angeles (Simcox and Pfister 1990). Foreignborn Hispanics in this study placed greater importance on "being with the family" as a reason for outdoor recreation than did either U.S.-born Hispanics or Anglo Americans, a pattern consistent with the process of Anglo-conformity.

Shaull's study also reported strong Anglo-conformity effects for naturerelated experiences in outdoor recreation. These experiences were most 
important to the least acculturated Hispanics. However, as language acculturation increased, there was a pattern of increasing similarity to Anglos in the reduced importance of these experiences.

Floyd and Gramann (1993) examined the effect of language acculturation on recreation participation (as opposed to style) of Mexican Americans living in the greater Phoenix area. After controlling for age and education, the least acculturated Mexican Americans were found to take part in significantly fewer activities than Anglos. This was true for four out of the five activity categories examined: water and snow-based activities, urban activities, consumptive recreation (i.e., fishing and hunting), and travel-oriented activities. Consistent with an Anglo-conformity hypothesis, both "bicultural" Mexican Americans and the most assimilated group differed from Anglos in only two of the five categories. Similarly, Baas, Ewert, and Chavez (1993) found that U.S.-born Hispanics were more similar to Anglos than to Mexican-born visitors in their participation in hiking, walking, and motorcycle riding. However, even the presumably more acculturated U.S.-born Hispanics were more like immigrants than Anglo Americans in their participation in other activities, such as group sports, picnicking, and target shooting.

Acculturation among Hispanic Americans may be related to facility and service preferences. Simcox and Pfister (1990) reported that Anglos and U.S.-born Hispanics visiting an outdoor recreation site in southern California were less concerned than Mexican and Central American-born visitors about insufficient law enforcement and insufficient information services.

\section{Acculturation and Perceived Discrimination}

Perceived discrimination in recreation settings has been viewed in recent research primarily as an "independent variable" that affects recreation participation. However, the perception of discrimination can also be treated as a "dependent variable" that is influenced by a variety of social and economic factors. One factor of particular interest is level of cultural assimilation. The basic question is as follows: "Do minority-group members with differing levels of acculturation also differ in their perceptions of discrimination in recreation areas?"

Two competing theoretical perspectives have addressed the influence of cultural assimilation on perceived discrimination (Floyd and Gramann 1995). The first perspective, known as the ethnic enclosure hypothesis, is based largely on Gordon's (1964) theory of ethnic assimilation. This hypothesis predicts that greater cultural assimilation will lead to reduced levels of perceived discrimination by minority-group members. As members of minority groups acquire greater knowledge of the dominant culture, become more socially integrated (i.e., develop more friendship and kinship ties with majority-group members), and experience upward social mobility, they should 
also experience greater acceptance into mainstream society and perceive less discrimination.

The second hypothesis, known as the ethnic competition hypothesis, makes the opposite prediction. This perspective is based on the work of Glazer and Moynihan (1963) and argues that increased knowledge of the dominant culture and a higher socioeconomic standing will lead to greater perceptions of discrimination. The logic behind this argument was stated by Portes (1984:385), drawing upon research among Cuban Americans in south Florida: "It is only when minorities start to abandon their internal colonies, neighborhoods, and enclaves and compete directly with other groups that awareness of racial and cultural differences will be heightened and form the basis for mobilization."

According to Portes, feelings of ethnic-group solidarity emerge as a form of boundary maintenance in defense of the social and economic interests of the ethnic group. Key to the maintenance of this solidarity is the shared perception among minority-group members of discrimination and persecution on the part of dominant groups. In the case of Cuban Americans, Portes, Parker, and Cobas (1980) found that greater upward socioeconomic mobility and knowledge of English (i.e., language acculturation) were associated with greater perceived discrimination, as was increased labor market participation outside of ethnic enclaves (Portes 1984).

A study by Floyd and Gramann (1995) found support for the ethnic enclosure hypothesis, but not the ethnic competition hypothesis. Mexican Americans in this study perceived less discrimination in recreation areas as their level of education (a measure of social mobility) increased and as their use and preference for English over Spanish increased. This finding is consistent with other research in a nonrecreation context (Aguirre, Saenz, and Hwang 1989), which found that educated persons of Mexican descent perceived lower levels of discrimination compared with those with less education.

\section{Summary}

Research on acculturation and recreation suggests that cultural assimilation may play an important role in shaping Hispanic Americans' (and perhaps Asian Americans') outdoor recreation behaviors and styles. In some cases, the dominant pattern appears to be one of Anglo-conformity, with ethnic behaviors and styles becoming progressively more Anglo-like as acculturation increases. In other cases, particularly those involving core ethnic values such as familism, the evidence for Anglo-conformity is less conclusive. In part, contradictions in research findings may be due to problems that arise from comparing results of regional household surveys with those of onsite visitor studies and because of differences in the way cultural assimilation is measured (i.e., as generational tenure or language acculturation). In addition, some studies have failed to control for other critical differences between culturalassimilation groups, such as age, income, and education, that could affect recreation style and participation. Also, it is not clear that assimilation studies 
can be easily applied (or are even relevant) to the African-American population in the U.S.

When considered as an independent variable, a small amount of research has found that, at least among Mexican Americans, perceptions of discrimination tend to decline with greater levels of assimilation into Anglo-American society. One consequence of this is that there may be major differences in opinions regarding the prevalence of discrimination in recreation areas, depending upon Mexican Americans' level of cultural and structural assimilation.

From an operations standpoint, research on acculturation and its relationship to outdoor recreation style and behavior is important. It may be that some sources of difficulty in the relationships between recreation resource managers and some immigrant groups may be less of an issue in subsequent years as the cultural assimilation of these groups progresses. 


\section{Applications of Recreation Ethnicity Research}

The application of social science research to policy, planning, and operations occurs frequently, but is rarely discussed in published materials (Weiss and Bucuvalas 1980). For this reason, there are relatively few articles or books that document these applications. Examples of those that were found are described below. Research applications are grouped into three categories that reflect the organization of the Corps of Engineers: policy and programs, planning, and operations.

\section{Policy and Programs}

Research on the recreation behavior and preferences of members of different ethnic groups has made important contributions to recreation policy and program development. In 1976, voters in the State of Missouri approved a constitutional amendment adding one-eighth cent to the State sales tax to fund an expanded conservation program (Wallace and Witter 1992). Because urban residents in the State voted most strongly for the amendment, the Missouri Department of Conservation felt that it was important to understand how fish, forests, and wildlife fit into urbanites' lifestyles and how the Department of Conservation might develop policies and programs that would enhance urban residents' opportunities for outdoor experiences. Because one of the expanded programs involved the development of a "system of Conservation Interpretive Centers with informed personnel to interpret for visitors" (Wallace and Witter 1992:20), a series of surveys and focus groups were conducted with white and African-American urban residents about current use and awareness of interpretive centers, desired facilities, and desired services. The results revealed the need for more in-close nature centers, that the "general public" was actually composed of many diverse publics, each with its own particular needs and concerns, and that proactive measures would be needed to attract more minority-group visitors to interpretive facilities. According to the Department of Conservation, the results of the studies were also useful in developing fundraising programs and membership campaigns, since they identified the different geographical markets served by existing interpretive facilities. 
A second example of the use of social science research in policy and program development comes from the USDA Forest Service. In 1991, the Forest Service, in partnership with several agencies and corporations, initiated the Urban Tree House program in a black neighborhood in Atlanta. The goals of the program were to increase the awareness among inner-city youth about urban trees and the benefits of their existence and to stimulate the interest of minority youth in natural resource careers (Samdahl and Kivel 1994). The "tree house" consisted of a large wooden deck in the shape of the United States built around an old water oak in a neighborhood park. Programs included after-school environmental education activities, information fairs, community picnics, and other neighborhood activities. Since the program was being extended to other cities, it was important to know how well it was achieving its objectives and if modifications in planning and programming were needed. Interviews conducted with community residents indicated that, while residents appreciated the value of environmental education, they felt that the Urban Tree House programs needed to be tied more directly to the reality of the everyday lives of their children. This included such issues as recycling, litter control, garden fertilization, and control of roaches and termites. Parents also emphasized the need for more hands-on activities and the integration of environmental education with recreational programming. Although the effort to raise the profile of natural resource careers was "politely" acknowledged, respondents indicated that these careers seemed small and remote for people who felt that their children might not finish school or live to be 20 . The evaluators concluded that, to succeed, the Urban Tree House program had to fully understand the cultural context in which it was operating and work within that world with a message that was relevant and meaningful. Specific suggestions for involving the local community more directly in planning and programming were offered.

\section{Planning}

Recreation planners are often required to involve affected publics, or "stakeholders," in the initial stages of planning for new facilities or in the rehabilitation of existing areas. Public involvement is especially important when current or potential users are racially or ethnically diverse. In such cases, planners may lack insight into the behavior, preferences, or motives of constituents from cultures other than their own. In addition, certain forms of involvement, such as public meetings, may be ineffective in contacting members of some ethnic groups.

The Chicago Park District, as part of its Lincoln Park Management and Restoration Plan, conducted multilingual surveys of park users representing 25 different ethnic groups to gather information on park images, activity preferences, locations and times of use, and problems associated with use, such as access, safety, facilities, management, and physical and social barriers to access (Friends of Lincoln Park 1991). According to a citizens-support group, the surveys provided an effective means for involving important 
constituents in the planning process who were not reached through other common involvement strategies.

The case of the Applewhite picnic area in the San Bernardino National Forest near Los Angeles illustrates how social science research can be applied to on-the-ground design changes when an area experiences major shifts in its use patterns (Chavez and Winter 1993). In this case, the picnic area was receiving more visitation than it was designed to accommodate, and most of the new users were no longer Anglo, but Hispanic. These visitors arrived in larger social groups and, while picnicking was still their main recreational activity, the manner in which it was done had changed substantially. Hispanic visitors often made their meals from scratch, which usually took several preparation hours onsite, contributing to the higher occupancy of the area. When the U.S. Forest Service was considering design changes to the site, it conducted a visitor survey in which users were asked to identify the single change in facilities that they considered to be most needed if only one change could be made. Increased parking capacity was cited as the most-needed improvement. In addition, users were asked to choose their preferred design alternative for the picnic area from color sketches depicting three different levels of development, ranging from "no development" to "much development." The first choice of respondents was for the most development, while the second choice was for the next-highest level of development.

\section{Operations}

Several studies conducted during the 1970 s and 1980s demonstrated that recreation resource managers are often unreliable sources of accurate information about their visitors (Absher et al. 1988; Clark, Hendee, and Campbell 1971; Hendee and Harris 1970). Wellman, Dawson, and Roggenbuck (1982) concluded that managers were best able to predict the motivations of their visitors in "traditional" recreation areas where visitors and managers were most likely to share the "contemplative ideal" of outdoor recreation. Such congruence is less likely in recreation areas where managers and visitors come from different ethnic backgrounds. For this reason, surveys of ethnically diverse visitor populations can provide feedback on operations that otherwise would not be available. Chavez, Baas, and Winter (1993) listed several changes in operations made by the BLM based on the results of a visitor survey at the Mecca Hills recreation area in southern California. Because it was found that many of the visitors were Hispanic and did not understand English, law enforcement personnel were trained in Spanish to improve their communication with users. Additionally, public service announcements related to the area were developed in Spanish for broadcast on a Spanishlanguage radio station in communities where survey data indicated many of the area's visitors lived. 


\section{Summary}

Research on the recreation behavior and styles of different ethnic groups has been applied to many practical problems in outdoor recreation, including policy and program development, planning, and day-to-day operations.

Because recreation managers and planners are unlikely to be well-informed about the preferences and attitudes of ethnically diverse populations, surveys and focus groups can provide valuable insights into the needs of distinctive groups and suggest ways to increase visitation and political support from traditionally underrepresented populations. 


\section{Research Needs}

The following major gaps in knowledge have been identified in this review that could be addressed in future research:

- Most research conducted with ethnically diverse visitor populations has been at sites where the primary mode of recreation participation is land based. Although substantial national and regional data exist on population participation rates in water-based recreation activities, there is almost no information on the recreational behaviors and styles of minority-group visitors to water-based outdoor recreation areas.

- Compared with other ethnic groups, there is a scarcity of data on the outdoor recreation behaviors, styles, and constraints of Asian Americans, an especially important population in the Pacific Coast States. This deficiency includes a lack of information on how cultural assimilation might affect the recreation styles of new Asian immigrants.

- While much anecdotal and focus-group evidence supports the salience of perceived discrimination as a cause of underutilization of recreation areas by minority-group members, it is not clear how widespread this perception is in the minority population. In addition, only one study was found that examined the effect of cultural assimilation on perceptions of discrimination in recreation settings.

- Changes in the ethnic composition of visitor populations may be producing displacement and avoidance effects in some recreation areas. However, no research has been done on where displaced recreationists go as an alternative. This is an especially salient issue in regions where many alternative recreation sites exist, exhibiting a range of facilities and service-development levels that appeal to different ethnic groups.

- Although several studies have been conducted on the language preferences of different visitor groups, no research was found that rigorously evaluated the effectiveness of different means of oral or written communication in promoting rule awareness and obedience at outdoor recreation sites. Such research has been conducted with white 
populations and has generally shown "communications-based management" to be effective in reducing many rule violations. However, it is not known whether this effectiveness can be extended to members of other ethnic groups.

The research needs and other findings identified in this literature review were used as input to discussion for developing a plan of study for the entire Ethnic Culture and Recreation Use work unit. Discussions in the plan of study meeting reinforced some of the data gaps identified in the review. The need for information on the recreation needs and preferences for Corps visitors, i.e., water-based recreation, was emphasized. Additionally, the need to understand who are the nonusers of the projects and why they are not using the resources was identified.

The major recommendations for the plan of study for the work unit were as follows:

- Recommended development of a process or methodology to obtain information on the recreation preference, styles, and values of ethnic groups. It was recognized the norms, values, and perceptions of groups may determine what method is most appropriate for a group, e.g., group response or relationship to authority such as a ranger uniform. The methodology would likely be made up of a core of questions with optional questions to be used as appropriate for each project.

- Recommended development of information describing what is known about the recreation styles, expectations, and values of different ethnic groups, for use in educating project personnel about the groups that use a project. 


\section{References}

Absher, J. D., McAvoy, L. H., Burdge, R. J., and Gramann, J. H. (1988). "Public and commercial managers predicting recreationist opinion," Journal of Park and Recreation Administration 6, 66-77.

Adams, C. E., and Moreno, M. (1994). “1994 survey of natural resource professionals in the United States," Report completed under contract No. TV-90038V (Tennessee Valley Authority), Texas Agricultural Experiment Station, Department of Wildlife and Fisheries Sciences, College Station, TX.

Adams, C. E., and Thomas, J. K. (1989). "Public uses of Texas wildlife and natural areas," Texas Agricultural Experiment Station technical report, College Station, TX.

Aguirre, B. E., Saenz, R., and Hwang, S. (1989). "Discrimination and the assimilation and ethnic competition perspectives," Social Science Quarterly 70, 594-606.

Allison, M. T. (1988). "Breaking boundaries and barriers: Future directions in cross-cultural research," Leisure Sciences 10, 247-259.

. (1993). "Access and boundary maintenance: Serving culturally diverse populations," Culture, conflict, and communication in the wildlandurban interface. A. W. Wert, D. J. Chavez, and A. W. Magill, ed., Westview Press, Boulder, CO, 99-107.

Anderson, E. (1978). "Visual resource assessment: Local perceptions of familiar natural environments," Unpublished Ph.D. diss., University of Michigan, Ann Arbor, MI.

Baas, J. M., Ewert, A., and Chavez, D. J. (1993). "Influence of ethnicity on recreation and natural environment use patterns: Managing recreation sites for ethnic and racial diversity," Environmental Management 17, 523529. 
Blahna, D., and Black, K. (1992). "Racism a concern for recreation managers." Managing urban and high-use recreation settings. P. H. Gobster, ed., General Technical Report NC-163, USDA Forest Service Northcentral Forest Experiment Station, St. Paul, MN, 111-118.

Buck, R. C. (1978). "Boundary maintenance revisited: Tourist experience in an old order Amish community," Rural Sociology 43, 221-234.

Bultena, G. L., and Field, D. R. (1978). "Visitors to national parks: A test of the elitism argument," Leisure Sciences 3, 221-240.

Burdge, R. J., and Opryszek, P. (1981). "Coping with change: An interdisciplinary study of the Lake Shelbyville Reservoir," IES Research Report No. 8, UILU-IES 81 0008, University of Illinois Institute for Environmental Studies, Urbana, IL.

Caraballo, J. A. (1993). "Música Tejana." Entre Otras Cosas. R. Curry, S. Dennis, P. Hanson, E. Bottino, J. A. Caraballo, F. Miller, and M. O. Pérez, ed., McGraw-Hill, New York, 85-89.

Carr, D. S., and Williams, D. R. (1993). "Understanding the role of ethnicity in outdoor recreation experiences," Journal of Leisure Research 25, 22-38.

Chavez, D. J. (1991). "Ethnic and racial group similarities and differences: A tool for resource managers." Abstracts From the 1991 Symposium on Leisure Research. C. Sylvester and L. Caldwell, ed., National Recreation and Park Association, Alexandria, VA.

. (1993). "Visitor perceptions of crowding and discrimination at two national forests in southern California," Research Paper PSW-RP-216, USDA Forest Service Pacific Southwest Research Station, Riverside, CA.

Chavez, D. J., Baas, J., and Winter, P. L. (1993). "Mecca Hills visitor research case study," Report BLM/CA/ST-93-005-9560, Bureau of Land Management, Sacramento, CA.

Chavez, D. J., and Winter, P. L. (1993). "Report for the Applewhite picnic area, Cajon Ranger District, San Bernardino National Forest," USDA Forest Service Pacific Southwest Research Station, Riverside, CA.

Cheek, N. H., Jr., Field, D. R., and Burdge, R. J. (1976). Leisure and recreation places. Ann Arbor Science Publishers, Ann Arbor, MI.

Christensen, J. C. (1992). "Standardization and component analysis of Simmons Market Research Data for 1980, 1981, 1985, and 1988; Age, ethnicity, and residence, by camping, salt water fishing, ice skating, jogging, roller skating, and horseback riding," Ohio State University School of Natural Resources, Columbus, $\mathrm{OH}$. 
Clark, R. N., Hendee, J. C., and Campbell, F. L. (1971). "Values, behavior and conflict in modern camping culture," Journal of Leisure Research $3,143-159$.

Clifford, F. (1995). “Opening parks to all of American," Article in the November 25, 1995, edition of the Los Angeles Times.

Cordell, H. K., Bergstrom, J. C., Hartmann, L. A., and English, D. B. K. (1990). "An analysis of the outdoor recreation and wilderness situation in the United States: 1989-2040," General Technical Report RM-189, USDA Forest Service Rocky Mountain Forest and Range Experiment Station, Fort Collins, CO.

Dennis, S., and Magill, A. W. (1991). "Professional disposition of wildland-urban interface recreation managers in southern California: Policy implications for the USDA Forest Service," Journal of Park and Recreation Administration 11, 31-41.

Dolin, E. J. (1988). “Black Americans' attitudes toward wildlife," Journal of Environmental Education 20, 17-21.

Dragon, C. (1986). "Native American underrepresentation in national parks: Tests of marginality and ethnicity hypotheses," Unpublished M.S. thesis, University of Idaho Department of Wildland Recreation Management, Moscow, ID.

Driver, B. L., Brown, P. J., and Peterson, G. L. (1991). Benefits of leisure. Venture Press, State College, PA.

Dunlap, R. E., and Van Liere, K. D. (1978). "The new environmental paradigm," Journal of Environmental Education 9, 10-19.

Dustin, D. L., Knopf, R. C., and Fox, K. M. (1993). "Building multicultural responsiveness into outdoor recreation management." Culture, conflict, and communication in the wildland-urban interface. A. W. Ewert, D. J. Chavez, and A. W. Magill, ed., Westview Press, Boulder, CO, 259265.

Dwyer, J. F. (1994). "Customer diversity and the future demand for outdoor recreation," General Technical Report RM-22, USDA Forest Service Rocky Mountain Forest and Range Experiment Station, Fort Collins, CO.

Dwyer, J. F., and Hutchison, R. (1990). "Outdoor recreation participation and preferences by Black and White Chicago households." Social Science and Natural Resource Recreation Management. J. Vining, ed., Westview Press, Boulder, CO, 49-67.

Eastman, C. (1991). "Community land grants: The legacy," Social Science Journal 28, 101-117. 
Ewert, A. W., Chavez, D. J., and Magill, A. W. (1993). Culture, conflict, and communication in the wildland-urban interface. Westview Press, Boulder, CO.

Field, D. R., and O'Leary, J. T. (1973). "Social groups as a basis for assessing participation in selected water activities," Journal of Leisure Research 5, 16-25.

Floyd, M. F. (1991). "Ethnic patterns in outdoor recreation participation: Effects of cultural and structural assimilation." Unpublished Ph.D. diss., Texas A\&M University Department of Recreation, Park and Tourism Sciences, College Station, TX.

Floyd, M. F., and Gramann, J. H. (1993). "Effects of acculturation and structural assimilation in resource-based recreation: The case of Mexican Americans," Journal of Leisure Research 25, 6-21.

. (1995). "Perceptions of discrimination in a recreation context," Journal of Leisure Research 27, 192-199.

Floyd, M. F., Gramann, J. H., and Saenz, R. (1993). "Ethnic factors and the use of public outdoor recreation areas: The case of Mexican Americans," Leisure Sciences 15, 83-98.

Floyd, M. F., Shinew, K. J., McGuire, F. A., and Noe, F. P. (1994). "Race, class, and leisure activity preferences: Marginality and ethnicity revisited," Journal of Leisure Research 26, 158-173.

Friends of Lincoln Park. (1991). "Ethnicity and recreation use in Lincoln Park," Article in Friends of Lincoln Park newsletter (November), Chicago, IL.

Froelicher, V. F., and Froelicher, E. S. (1991). "Cardiovascular benefits of physical activity." Benefits of leisure. B. L. Driver, P. J. Brown, and G. L. Peterson, ed., Venture Press, State College, PA, 59-72.

Frome, M. (1969). Editorial column, American Forests 3(Jan.), 40.

Glass, R. J., Muth, R. M., and Flewelling, R. (1990). "Distinguishing recreation from subsistence in a modernizing economy." Social science and natural resource recreation management. J. Vining, ed., Westview Press, Boulder, CO, 151-164.

Glazer, N., and Moynihan, D. (1963). Beyond the melting pot. MIT and Harvard University Press, Cambridge, MA. 
Gobster, P. H. (1992). "Forest vegetation in urban parks: Perceptions of inner city children." Proceedings of the 1991 Northeastern Recreation Research Symposium. G. A. Vander Stoep, ed., General Technical Report NE-160, USDA Forest Service Northeastern Forest Experiment Station, Radnor, PA, 209-214.

Gobster, P. H., and Delgado, A. (1992). "Ethnicity and recreation use in Chicago's Lincoln Park: In-park user survey findings." Managing urban parks and high-use recreation settings. P. H. Gobster, ed., General Technical Report NC-163, USDA Forest Service Northcentral Forest Experiment Station, St. Paul, MN, 75-81.

Gordon, M. (1964). Assimilation in American life: The role of race, religion, and national origins. Oxford University Press, New York.

. (1978). Human nature, class, and ethnicity. Oxford University Press, New York.

Gramann, J. H. (1983). "An ex post facto analysis of the regional economic impact of expenditures for reservoir recreation," Journal of Environmental Management 16, 357-367.

. (1991). "Visitors, alternative futures, and recreational displacement at Yosemite National Park," Technical report completed under cooperative agreement CA-7029-0-0005 with the Western Regional Office, National Park Service, Texas A\&M University Department of Recreation, Park and Tourism Sciences, College Station, TX.

Gramann, J. H., and Floyd, M. F. (1991). "Ethnic assimilation and recreational use of the Tonto National Forest," Technical report on file with the Wildland Recreation and Urban Culture Project, USDA Forest Service Pacific Southwest Research Station, Riverside, CA.

Gramann, J. H., Floyd, M. F., and Ewert, A. (1992). "Interpretation and Hispanic American ethnicity." On interpretation: Sociology for interpreters of natural and cultural history. G. E. Machlis and D. R. Field, ed., Oregon State University Press, Corvallis, OR, 161-177.

Gramann, J. H., Floyd, M. F., and Saenz, R. (1993). "Outdoor recreation and Mexican American ethnicity: A benefits perspective." Culture, conflict, and communication in the wildland-urban interface. A. W. Ewert, D. J. Chavez, and A. W. Magill, ed., Westview Press, Boulder, CO, 6984.

Gramann, J. H., and Saenz, R. (1995). “Attitudes of Anglo and Hispanic residents toward the Lower Rio Grande Valley Wildlife Corridor," Paper presented at the U.S./Mexico Border States Conference on Recreation, Parks, and Wildlife, Brownsville, TX. 
Hady, T. F., and Ross, P. J. (1990). "An update: The diverse social and economic structure of nonmetropolitan America," AGES9036, U.S. Department of Agriculture, Washington, DC.

Hales, D. F. (1991). “The Pinelands National Reserve: An approach to cooperative conservation." Resident peoples and national parks. P. C. West and S. R. Brechin, ed., University of Arizona Press, Tucson, 239-250.

Hendee, J. C., and Harris, R. W. (1970). "Foresters' perceptions of wilderness-user attitudes and preferences," Journal of Forestry 68(Dec.), 759-762.

Henderson, K. A. (1990). "The meaning of leisure for women: An integrative review of the research," Journal of Leisure Research 22, 228-243.

Henderson, K. A., Bialscheki, M. D., Shaw, S. M., and Freysinger, V. J. (1989). A leisure of one's own: A feminist perspective on women's leisure. Venture, University Park, PA.

Howard, D. R., and Crompton, J. L. (1984). "Who are the consumers of public park and recreation services? An analysis of the users and nonusers of three municipal leisure service organizations," Journal of Park and Recreation Administration 2(3), 33-48.

Hutchison, R. (1987). "Ethnicity and urban recreation: Whites, Blacks and Hispanics in Chicago's public parks," Journal of Leisure Research 19, 205-222.

. (1988). "A critique of race, ethnicity, and social class in recent leisure-recreation research," Journal of Leisure Research 20, 10-30.

. (1992). "Hmong leisure and recreation activity." Managing urban and high-use recreation settings. P. H. Gobster, ed., General Technical Report NC-163, USDA Forest Service Northcentral Forest Experiment Station, St. Paul, MN, 87-92.

Irwin, P. N., Gartner, W. G., and Phelps, C. C. (1990). “Mexican American/Anglo cultural differences as recreation style determinants," Leisure Sciences 12, 335-348.

Johnson, K. M., and Beale, C. L. (1994). "The recent revival of widespread population growth in nonmetropolitan areas of the United States," Rural Sociology 59, 655-667.

Kaplan, R., and Kaplan, S. (1989). The experience of nature: A psychological perspective. Cambridge University Press, New York. 
Kaplan, R., and Talbot, J. F. (1988). "Ethnicity and preference for natural settings: A review and recent findings," Landscape and Urban Planning $15,107-117$.

Keefe, S. E. (1984). "Real and ideal extended familism among Mexican Americans and Anglo Americans: On the meaning of "close" family ties," Human Organization 43, 65-70.

Keefe, S. E., and Padilla, A. M. (1987). Chicano ethnicity. University of New Mexico Press, Albuquerque, NM.

Kellert, S. R. (1984). "Urban American perceptions of animals and the natural environment," Urban Ecology 8, 209-228.

Kelly, J. R. (1983). Leisure identities and interactions. Allen and Unwin, London.

lan, New York.

(1987). Freedom to be: A new sociology of leisure. Macmil-

Klobus-Edwards, P. K. (1981). "Race, residence, and leisure style: Some policy implications," Leisure Sciences 4, 95-112.

Knowlton, C. S. (1972). "Culture, conflict and natural resources." Social behavior, natural resources and the environment. W. Burch, Jr., N. H. Cheek, Jr., and L. Taylor, ed., Harper and Row, New York, 109-145.

Lee, R. G. (1972). "The social definition of outdoor recreational places." Social behavior, natural resources, and the environment. W. R. Burch, Jr., N. H. Cheek, Jr., and L. Taylor, ed., Harper and Row, New York, 68-84.

Long, P. T., Perdue, R. R., and Allen, L. R. (1990). "Rural resident community life satisfaction and tourism development attitudes: A comparison of forest and nonforest community residents." Contributions of social sciences to multiple-use management: An update. B. L. Driver, comp., General Technical Report RM-196, USDA Forest Service Rocky Mountain Forest and Range Experiment Station, Fort Collins, CO, 57-75.

Loomis, C. P., and Beegle, J. A. (1957). Rural sociology: The strategy of change. Prentice-Hall, Englewood Cliffs, NJ.

Lynch, B. D. (1993). "The garden and the sea: U.S. Latino environmental discourse and mainstream environmentalism," Social Problems 40, 108124.

Malveaux, J. (1988). "Ain't I a woman? Differences in the labor market status of black and white women." Racism and sexism: An integrated study. P. S. Rothenberg, ed., St. Martin's Press, New York, 76-80. 
Marger, M. N. (1985). Race and ethnic relations: American and global perspectives. Wadsworth Publishing Co., Belmont, CA.

Market Opinion Research. (1986). "Participation in outdoor recreation among American adults and the motivations which drive participation," Report prepared for the President's Commission on Americans Outdoors.

Maslow, A. H. (1975). Motivation and personality. 2nd ed., Viking Press, New York.

McGuire, F. A., O'Leary, J. T., Alexander, P. B., and Dottavio, F. D. (1987). "A comparison of outdoor recreation preferences and constraints of black and white elderly," Activities, Adaptations and Aging 9, 95-104.

McLemore, S. D. (1991). Racial and ethnic relations in America. Allyn and Bacon, Inc., Boston.

Medina, A. Q. (1983). “A visual assessment of children's and environmental educators' urban residential preference patterns," Unpublished Ph.D. diss., University of Michigan, Ann Arbor, MI.

Meeker, J. W. (1992). "Red, white, and black in the national parks." On interpretation: Sociology for interpreters of natural and cultural history. G. E. Machlis and D. R. Field, ed., Oregon State University Press, Corvallis, $\mathrm{OR}$.

Mueller, G., and Guerin, G. (1962). "Participation in outdoor recreation behavior: Factors affecting demand among American adults," Study Report 20, Outdoor Recreation Resources Review Commission, U.S. Government Printing Office, Washington, DC.

Murdock, S. H., Backman, K., Colberg, E., Hoque, M. R., and Hamm, R. R. (1990). "Modeling demographic change and characteristics in the analysis of future demand for leisure services," Leisure Sciences 12, 79102.

Murdock, S. H., Backman, K., Hoque, M. D., and Ellis, D. (1991). "The implications of change in population size and composition on future participation in outdoor recreational activities," Journal of Leisure Research 23, 238-259.

Napier, T. L. (1981). Outdoor recreation planning, perspectives, and research. Kendall/Hunt Publishing, Dubuque, IA.

Noe, F. P., and Snow, R. (1989/90). "Hispanic cultural influence on environmental concern," Journal of Environmental Education 21, 27-34. 
O'Leary, J. T., and Benjamin, P. J. (1982). "Ethnic variation in leisure behavior: The Indiana case," Indiana Agricultural Experiment Station Bulletin No. 349, Purdue University, West Lafayette, IN.

Outley, C. W. (1995). "The influence of perceived discrimination in determining recreation behavior of African Americans in southern Illinois," Presentation at the 19th annual Graduate Research Symposium of the Department of Recreation, Park, and Tourism Sciences, Texas A\&M University, College Station, TX.

Parks, H. B. (1988). A history of Mexico. Houghton Mifflin, Boston.

Portes, A. (1984). "The rise of ethnicity: Determinants of ethnic perceptions among Cuban exiles in Miami," American Sociological Review 49, 383-397.

Portes, A., Parker, R. N., and Cobas, J. (1980). “Assimilation or consciousness: Perceptions of U.S. society among recent Latin American immigrants to the United States," Social Forces 59, 200-224.

Poudel, P. K. (1979). "Capitalization of environmental values into property values: Literature review," General Technical Report RM-69, USDA Forest Service Rocky Mountain Forest and Range Experiment Station, Fort Collins, CO.

Pizzini, M. V., Latoni, A., and Rodríguez, V. (1993). "El Yunque or the Caribbean National Forest? Meaning, management, and culture in the urban-tropical forest interface." Culture, conflict, and communication in the wildland-urban interface. A. W. Ewert, D. J. Chavez, and A. W. Magill, ed., Westview Press, Boulder, CO, 69-84.

Reiling, S. D., McCarville, R. E., and White, C. M. (1994). "Demand and marketing study at Army Corps of Engineers day-use areas," Miscellaneous Paper R-94-1, U.S. Army Corps of Engineers Waterways Experiment Station, Vicksburg, MS.

Sabogal, F., Marín, G., Otero-Sabogal, R., Marín, B. V., and Perez, Stable, J. (1987). "Hispanic familism and acculturation: What changes and what doesn't?" Hispanic Journal of Behavioral Sciences 9, 397-412.

Samdahl, D. M., and Kivel, B. (1994). "Community assessment of the Atlanta Urban Tree House," Contract report completed for the USDA Forest Service Southeastern Forest Experiment Station, University of Georgia Department of Recreation and Leisure Studies, Athens, GA.

Schreyer, R., and Knopf, R. C. (1984). "The dynamics of change in outdoor recreation environments-Some equity issues," Journal of Park and Recreation Administration 2, 9-19. 
Scott, D. (1993). "Use and non-use of public parks in northeast Ohio: Differences between African-Americans and Whites." Proceedings of the 1993 Northeastern Recreation Research Symposium. G. A. Vander Stoep, ed., General Technical Report NE-185, USDA Forest Service Northeastern Forest Experiment Station, Radnor, PA, 224-227.

Scott, D., and Munson, W. (1994). "Perceived constraints to park usage among individuals with low incomes," Journal of Park and Recreation Administration 12, 79-96.

Shaull, S. L. (1993). "Family-related and nature-related recreation benefits among anglo Americans and Hispanic Americans: A study of acculturation and primary structural assimilation," Unpublished M.S. thesis, Texas A\&M University Department of Recreation, Park and Tourism Sciences, College Station, TX.

Siegel, P. B., and Leuthold, F. O. (1992). "Economic and fiscal impacts of Tellico Village, Loudon County, Tennessee," Research Report 92-17, University of Tennessee Agricultural Experiment Station, Knoxville, TN.

Simcox, D. (1991). "Land ethics: Philosophical background and cultural variations," Trends 28, 15-20.

Simcox, D. E., and Pfister, R. E. (1990). "Hispanic values and behavior related to outdoor recreation and the environment," USDA Forest Service Contract Report, USDA Forest Service Pacific Southwest Research Station, Riverside, CA.

Snow, R. (1989). "Biscayne National Park visitor survey: Final report," National Park Service Cooperative Park Studies Unit Technical Report, Georgia State University, Atlanta.

Stamps, S. M., Jr., and Stamps, M. B. (1985). "Race, class and leisure activities of urban residents," Journal of Leisure Research 17, 40-56.

Taylor, D. E. (1989). "Blacks and the environment: Toward an explanation of the concern and action gap between blacks and whites," Environment and Behavior 21, 175-205.

. (1992). "Urban park use: Race, ancestry, and gender." Managing urban and high-use recreation settings. P. H. Gobster, ed., General Technical Report NC-163, USDA Forest Service Northcentral Forest Experiment Station, St. Paul, MN, 82-86.

Teske, R. H., Jr., and Nelson, B. (1976). "An analysis of differential assimilation rates among middle-class Mexican Americans," Sociological Quarterly 17, 218-235. 
Ulrich, R. S., Dimberg, U., and Driver, B. L. (1991). "Psychophysiological indicators of leisure benefits." Benefits of leisure. B. L. Driver, P. J. Brown, and G. L. Peterson, ed., Venture Press, State College, PA, 73-89.

U.S. Bureau of the Census. (1994). "Projections of the population, by age, sex, race, and Hispanic origin, for the United States: 1993-2050," Current Population Report Series P25-1104, U.S. Government Printing Office, Washington, DC.

U.S. Census, 1990: Nation-race of householder by household type (Online). (1995). Available URL: http//cedr.lbl.gov/cdrom/lookup.

USDA Forest Service North Central Forest Experiment Station. (1994). "Recreation opportunity and cultural diversity: A summary of research," USDA Forest Service North Central Forest Experiment Station, Chicago.

USDI National Park Service. (1986). 1982-1983 nationwide recreation survey. U.S. Government Printing Office, Washington, DC.

U.S. Fish and Wildlife Service. (1988). "1985 national survey of fishing, hunting, and wildlife associated recreation," U.S. Fish and Wildlife Service, Washington, DC.

U.S. Fish and Wildlife Service and U.S. Bureau of the Census. (1982). "1980 national survey of fishing, hunting, and wildlife-associated recreation." U.S. Government Printing Office, Washington, DC.

van den Berghe, P. L. (1976). "Ethnic pluralism in industrial societies: A special case?" Ethnicity 3, 242-255.

Veblen, T. (1899). The theory of the leisure class. Macmillan, New York.

Wallace, V. K., and Witter, D. J. (1992). "Urban nature centers: What do our constituents want and how can we give it to them?" Legacy 2(2), 2024.

Washburne, R. F. (1978). "Black under-participation in wildland recreation: Alternative explanations," Leisure Sciences 1, 175-189.

Washburne, R., and Wall, P. (1980). "Black-white ethnic differences in outdoor recreation," Research Paper INT-249, USDA Forest Service Intermountain Forest and Range Experiment Station, Ogden, UT.

Watson, A. E., and Cordell, H. K. (1990). "Impacts of resource-based tourism on local income and employment." Contributions of social sciences to multiple-use management: An update. B. L. Driver, comp., General Technical Report RM-196, USDA Forest Service Rocky Mountain Forest and Range Experiment Station, Fort Collins, CO. 
Weiss, C. H., and Bucuvalas, M. J. (1980). Social science research and decision-making. Columbia University Press, New York.

Wellman, J. D. (1987). Wildland recreation policy. John Wiley and Sons, New York.

Wellman, J. D., Dawson, M. S., and Roggenbuck, J. W. (1982). "Park managers' predictions of the motivations to two National Park Service areas," Journal of Leisure Research 14, 1-15.

West, P. C. (1982). "A nationwide test of the status group dynamics approach to outdoor recreation demand," Leisure Sciences 5, 1-34.

(1984). "Status differences and interpersonal influence in the adoption of outdoor recreation activities," Journal of Leisure Research 16, 350-354.

. (1985). "Predicting the direction of participation rate trends with the status group dynamics approach to recreation demand." Proceedings 1985 National Outdoor Recreation Trends Symposium II. Vol. II, J. Wood, ed., USDI National Park Service, Atlanta, GA, 362-370.

. (1988). "Urban region parks and Black minorities: Subculture, marginality, and interracial relations in park use in the Detroit Metropolitan Area," Leisure Sciences 5, 1-18.

. (1993). "The tyranny of metaphor: Interracial relations, minority recreation, and the wildland-urban interface." Culture, conflict, and communication in the wildland-urban interface. A. W. Ewert, D. J. Chavez, and A. W. Magill, ed., Westview Press, Boulder, CO, 109-115.

Williams, D. R., and Carr, D. S. (1993). "The sociocultural meanings of outdoor recreation places." Culture, conflict, and communication in the wildland-urban interface. A. W. Ewert, D. J. Chavez, and A. W. Magill, ed., Westview Press, Boulder, CO, 209-219.

Yetman, N. R. (1985). Majority and minority: The dynamics of race and ethnicity in American life. 4th ed., Allyn and Bacon, Boston.

Yinger, J. M. (1981). “Toward a theory of assimilation and dissimilation," Ethnic and Racial Studies 4, 249-264. 


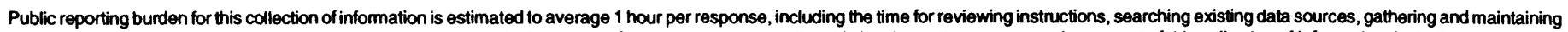

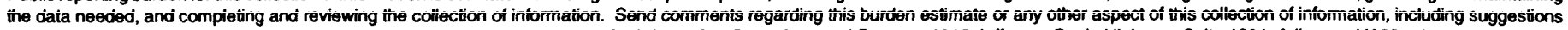

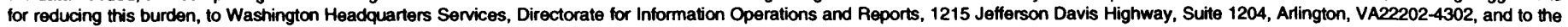
Office of Management and Budget, Paperwork Reduction Project (0704-0188), Washington, DC20503.

1. AGENCY USE ONLY (Leầe tolankí)
3. REPORT TYPE AND DATES COVERED Final report

\section{REPORT DATE March 1996}

5. FUNDING NUMBERS
4. TITLE AND SUBTITLE

Ethnicity, Race, and Outdoor Recreation: A Review of Trends, Policy, and Research

6. AUTHOR(S)

James H. Gramann

7. PERforming ORganization NAME(S) AND ADDRESS(ES)

Department of Recreation, Park, and Tourism Sciences

Department of Rưal Sociology

Texas A\&M University

College Station. TX 77843-2261

9. SPONSORINGMONITORING AGENCY NAME(S) AND ADDRESS(ES)

U.S. Army Corps of Engineers

Washington, DC 20314-1000

U.S. Ârmy Engineer Waterways Experiment Station

3909 Hall Ferry Road, Vicksburg, MS 39180-6199
8. PERFORMING ORGANIZATION REPORT NUMBER

11. SUPPLEMENTARY NOTES

Available from National Technical Information Service, 5285 Port Royal Road, Springfield, VA 22161.

12a. DISTRIBUTIONAVAILABILITY STATEMENT

Approved for public release; distribution is unlimited. 12b. DISTRIBUTION CODE

10. SPONSORINGMONITORING AGENCY REPORT NUMBER

Miscellaneous Paper R-96-1

\section{ABSTRACT (Maximum 200 words)}

This literature review was performed as the initial work of the U.S. Army Corps of Engineers in investigating and providing for recreation use of ethnic groups. This report reviews the social science literature describing ethnic and racial differences in recreation and leisure behavior and summarizes the national policy context for that research. Major sections of the review include demographic trends in the ethnic and racial composition of the United States; national ethnic policy as reflected in the statutes and regulations of the United States relevant to ethnicity, race, and outdoor recreation; a review of current research programs on ethnicity and recreation in the major Federal recreation resource agencies; overview of major research issues in studies of ethnicity and recreation; and applications of recreation ethnicity research to Federal agency programs. Significant data gaps identified include no information on recreation behavior and styles of minority-group visitors to water-based recreation areas; little information on perceptions of discrimination as a cause of underutilization of recreation areas by minority groups; no research done on effects of displacement and avoidance in recreation areas caused by changes in ethnic composition of visitors; and no research found that evaluated the effectiveness of communications-based resource management for members of ethnic groups.

\section{SUBJECT TERMS}

Acculturation

Assimilation

Ethnic diversity
Ethnic group

Ethnicity

Outdoor recreation
Race

Racial diversity

Recreation use
15. NUMBER OF PAGES 88

16. PRICE CODE

\section{SECURITY CLASSIFICATION 1 18. SECURITY CLASSIFICATION 19 . SECURITY CLASSIFICATION 20. LIMITATION OF ABSTRACT OF REPORT \\ OF ABSTRACT}

UNCLASSIFIED 
Destroy this report when no longer needed. Do not return it to the originator. 